Florida International University FIU Digital Commons

FIU Electronic Theses and Dissertations

University Graduate School

11-18-2015

\title{
The Development of a Novel Polymer Based System for Gene Delivery
}

Anh Van Le

FIU, ale001@fiu.edu

DOI: $10.25148 /$ etd.FIDC000210

Follow this and additional works at: https://digitalcommons.fiu.edu/etd

Part of the Biomaterials Commons, Nanoscience and Nanotechnology Commons, and the Polymer and Organic Materials Commons

\section{Recommended Citation}

Le, Anh Van, "The Development of a Novel Polymer Based System for Gene Delivery" (2015). FIU Electronic Theses and Dissertations. 2314.

https://digitalcommons.fiu.edu/etd/2314

This work is brought to you for free and open access by the University Graduate School at FIU Digital Commons. It has been accepted for inclusion in FIU Electronic Theses and Dissertations by an authorized administrator of FIU Digital Commons. For more information, please contact dcc@fiu.edu. 


\section{FLORIDA INTERNATIONAL UNIVERSITY}

Miami, Florida

\section{THE DEVELOPMENT OF A NOVEL POLYMER BASED SYSTEM FOR GENE DELIVERY}

A thesis submitted in partial fulfillment of

the requirements for the degree of

MASTER OF SCIENCE

in

BIOMEDICAL ENGINEERING

by

Anh Van Le 
To: $\quad$ Interim Dean Ranu Jung

College of Engineering and Computing

This thesis, written by Anh Van Le, and entitled The Development of a Novel Polymer Based System for Gene Delivery, having been approved in respect to style and intellectual content, is referred to you for judgement.

We have read this thesis and recommend that it be approved.

$\begin{array}{r}\text { Anthony J. McGoron } \\ \hline \text { Chenzhong Li }\end{array}$

Date of Defense: November 18, 2015

The thesis of Anh Van Le is approved.

Interim Dean Ranu Jung

College of Engineering and Computing

Dean Lakshmi N. Reddi University Graduate School

Florida International University, 2015 


\section{ACKNOWLEDGMENTS}

I first like to thank my family and friends whose support was very much needed during the process of completing my Master's degree. I would also like to thank the Biomedical Engineering Department Faculty and Staff for their support through the completion of my master thesis. They were instrumental in providing necessary funding for needed reagents to expedite the completion of my research. I would also like to thank FIU BRI for providing a \$2500 grant to fund my summer research. I am also very grateful to my former lab mate, Xizi Dai, for providing input and knowledge on key questions I had during my initial foray into my research. I would especially like to thank my fellow graduate student, Vinay Bhardwaj, for answering my many questions on Raman Spectra, how to use the instrument and ways to get better peaks for characterizing my polymer. Also Dr. Moon and Tereza Votka from his lab group for allowing me to use the instrumentation in his lab for GPC analysis of my polymers. I would also like to thank my mentor Tatiana Slepak of the LemBix Lab (Miami Project Cure for Paralysis, University of Miami) for generously providing much needed HEK 293 cells. Lastly, I would like to thank my former major professor Dr. Yen-Chih Huang for his initial guidance in my research and his timely help in identifying other avenues for modifying my polymers. Without him I would have continue to attempt modifying my polymer with the same reagent that wouldn't work. 


\begin{abstract}
OF THE THESIS
THE DEVELOPMENT OF A NOVEL POLYMER BASED SYSTEM FOR GENE
\end{abstract}

\title{
DELIVERY
}

by

Anh Van Le

Florida International University, 2015

Miami, Florida

Professor Wei-Chiang Lin, Major Professor

Gene therapy involves the use of nucleic acids, either DNA or RNA for the treatment, cure, or prevention of human diseases. Synthetic cationic polymers are promising as a tool for gene delivery because of their high level of design flexibility for biomaterial construction and are capable of binding and condensing DNA through electrostatic interactions.

Our lab has developed a novel polymer (poly (polyethylene glycol-dodecanoate) (PEGD), a polyester of polyethylene glycol (PEG) and dodecanedioic acid (DDA). PEGD is a linear viscous polymer that self-assembles into a vesicle upon immersion in an aqueous solution. A copolymer of dodecanedioc acid and polyethylene glycol (PEG) was synthesized at a 1:1 ratio. Furmaric (FA) or itaconic acid (IA) was used to suppress DDA in the PEGD copolymer at an 80:20 ratio (DDA: furmaric/itaconic acid) to form the PEGDF/I variant. PEGDF/I are then modified through the Michael addition of Protamine Sulfate (PEGDF/I-PS) and Cys-Arg ${ }_{8}$ (PEGDF/I-CA) peptide to the carbon-carbon double bond on the polymer backbone to introduce a positive charge.

The modified PEGDF/I polymers were capable of binding and condensing DNA. Transfection of HEK 293 cells with pTurboGFP plasmid using modified PEGDF/I 
polymers was successful but showed varied efficiency. The PEGDF/I-CA polymer had around 30\% transfection efficiency and was shown to be non-cytotoxic. 


\section{TABLE OF CONTENTS}

\section{CHAPTER}

PAGE

1. Literature Review........................................................................................

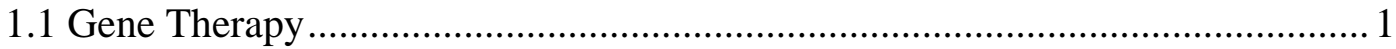

1.2 Viral vectors for the delivery of genetic material ............................................... 1

1.3 Non-viral systems for the delivery of genetic material.......................................... 4

1.3.1 Physical forces as a gene delivery method ........................................... 5

1.3.2 Cationic Lipids for gene delivery ………………...............................

1.4 Cationic Polymers .............................................................................................

1.4.1 Mechanism of action.....................................................................

1.4.1.1 DNA Binding and determination of N/P ratio ....................... 8

1.4.1.2 Internalization of cationic polymers ...................................... 9

1.4.1.3 Endosomal escape ................................................................ 9

1.4.2 Cationic polymers in used................................................................ 10

1.4.2.1 Poly(ethyleneimine) (PEI) ...................................................10

1.4.2.2 Poly(L-Lysine) (PLL) ......................................................11

1.4.2.3 Chitosan ........................................................................... 12

1.4.2.4 Dendrimers........................................................................ 12

1.5 Novel polymer: poly(PEG-Dodecanoate) (PEGD) .............................................. 13

1.5.1 Polyethylene glycol (PEG) ............................................................ 14

1.5.2 Dodecanedioic acid (DDA) .............................................................. 14

1.5.3 Furmaric acid ............................................................................. 14

1.5.4 Itaconic acid................................................................................. 15

1.5.5 Addition of FA and IA to PEGD backbone....................................... 15

1.5.6 Cys-(Arg)n ................................................................................. 15

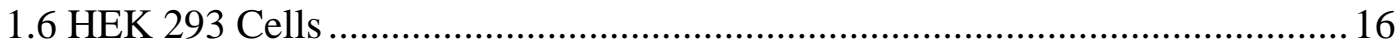

1.7 Alamar Blue Cytotoxicity ............................................................................... 16

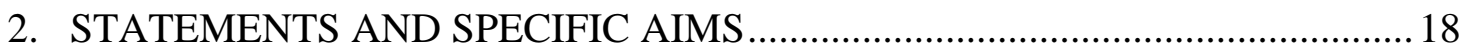

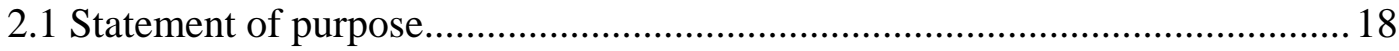

2.2 Specific Aims ............................................................................................. 18

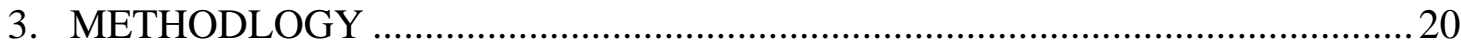

3.1 Synthesizing polymer................................................................................ 20

3.1.1 Preparation of PEGDF and PEGDI.................................................20

3.1.2 Acquiring of Cys-Arg8 and protamine sulfate.....................................22

3.1.3 Modification of PEGDF and PEGDI with Cys-Argn and Protamine

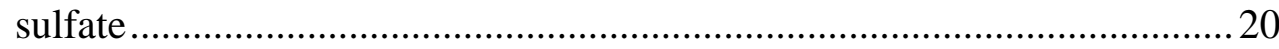

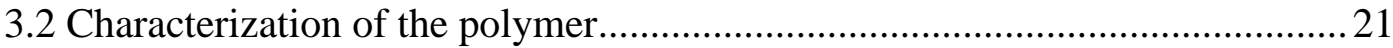

3.2.1 Raman Spectroscopy.......................................................................21

3.2.2 Gel Permeation Chromatography ………………………………......22

3.2.3 Dynamic Light Scattering (DLS).........................................................22

3.3 Determination of modified PEGD transfection capabilities ...............................22 
3.3.1 Determination of modified PEGDF and PEGDI binding capabilities

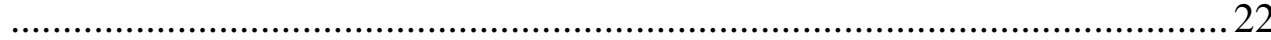

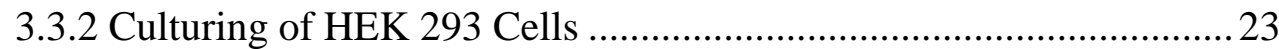

3.3.3 Cell viability via Alamar Blue Assay ………………………………...23

3.3.4 Transfection study in HEK 293 cells ..................................................2 24

3.3.5 Transfection efficiency ..................................................................2 24

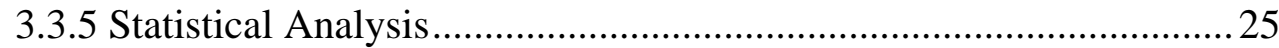

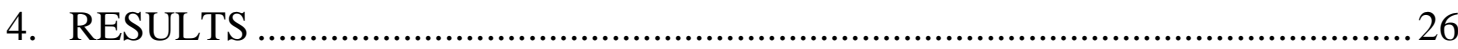

4.1 Results accomplished for Specific Aim 1 …………....................................2. 26

4.1.1 Raman Spectra of PEGDF/I Poylmers...............................................26

4.1.2 Dynamic Light Scattering of modified PEGDF/I polymers ...............27

4.1.3 GPC of PEGDF/PEGDI polymers ....................................................28

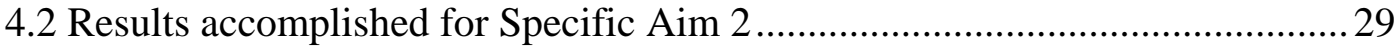

4.2.1 DNA Binding Assay ........................................................................29

4.2.2 In vitro cytotoxicy analysis of modified PEGDF/I polymers by

alamar blue assay .......................................................................................... 31

4.2.3 Transfection of HEK 293 cells ......................................................... 32

4.2.4 Cell Profiler image analysis of transfected cells..................................33

4.2.5 Transfection efficiency in HEK 293 cells............................................ 35

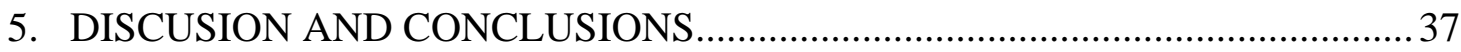

5.1 Characterization of PEGDF and PEGDI polymers..............................................37

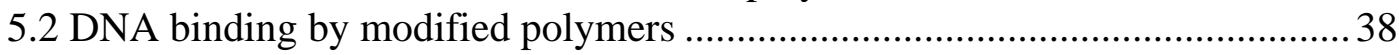

5.3 In vitro cytotoxicity analysis of modified PEGDF/I polymers .............................39

5.4 Cell Profiler image analysis ..............................................................................4 40

5.5 Transfection of HEK 293 cells .....................................................................4

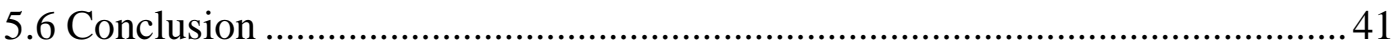




\section{LIST OF FIGURES}

FIGURE

PAGE

Figure 1. PEGD polycondensation reaction of PEG and DDA monomers................12

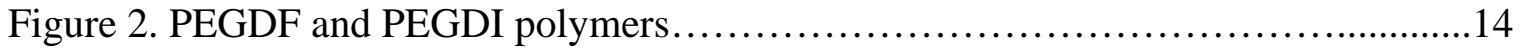

Figure 3. Raman spectrum of PEGDF and PEGDI Polymers shows peaks at $1735 \mathrm{~cm}^{-1}$

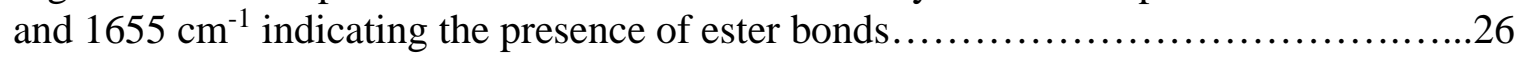

Figure 4. Mean size and PDI values for Modified PEGDF and PEGDI)................27

Figure 5. GPC measurements of PEGDF and PEGDI polymers. A change in MW from 24 hrs to 48 hrs showed polymer elongation by esterification.

Figure 6. Gel binding assay. PEGDF and PEGDI modified with protamine sulfate (PS) and Cys-Arginine (CA) were capable of binding and retarding the migration of GFP

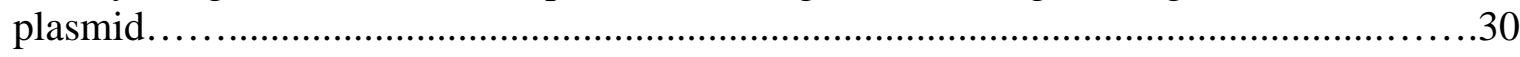

Figure 7. Gel binding assay. Unstained image of agarose gel under normal light.............30

Figure 8. Alamar Blue Assay of modified polymers. Statistical testing shows that PEGDF-PS, PEGDI-PS, and PEI exhibit cytotoxicity when compared to the control.......32

Figure 9. Transfection of HEK293 cells with modified PEGDF and PEGDI Polymers. A. Phase contrast of 48 post transfection. B. Same field fluorescence microscopy of HEK 293

Figure 10. Cell Profiler Image analysis of bright-field microscopy images...............34

Figure 11. Cell Profiler image analysis of fluorescence microscope images of $24 \mathrm{hr}$ Post transfection. 35

Figure 12. Transfection in HEK293 cells. .36 


\section{CHAPTER 1 LITERATURE REVIEW}

\subsection{Gene therapy}

The concept of using genes as a drug for human disease therapy was originally conceived around the early 1970's as a result of our increased understandings of human gene function, how their mutations impacted cellular behavior, and the development of more effective methods for the delivery of DNA into mammalian cells (6). Gene therapy involves the use of nucleic acids, either DNA or RNA, for the treatment, cure, or prevention of human diseases (1-3). The underlying idea of gene therapy involves the transfer of genetic material into specific cells responsible for diseases. Depending upon the type of disease, gene therapy can be employed to either replace missing or defective endogenous genes with a functional copy or by reducing (or silencing) the production of harmful or defective gene products $(2,4)$. Although the concept of gene therapy is promising for treating diseases, the transfer of genetic material into higher organisms still remains an enormous technical challenge. The hydrophobic and apolar membranes of mammalian cells presents a formidable barrier for the movement of large polyanion such as DNA and RNA from the extracellular space into the cytosol (6). Thus, the fundamental challenge for successful gene therapy is finding both a safe and effective delivery system to facilitate the transfer of nucleic materials. Currently, the delivery of genetic material can be divided into two categories: viral and non-viral methods (1-4).

\subsection{Viral vectors for the delivery of genetic material}

Viral delivery of genetic material, also known as transduction, is a delivery method in which we exploit the ability of viruses to transfer DNA into target cells. Viruses have evolved over millions of years an efficient mechanism to internalize their 
own genome into targeted cells. A viral particle can be viewed simply as a nano-sized object composed of nucleic acid and a few proteins that can prevent its degradation in the extracellular environment, and also facilitate its internalization into cells. The basic approach of viral gene delivery involves the packaging of DNA into a virus particle and the transfer of gene by the normal viral infection route. Since viruses are naturally pathogenic, steps must be taken to eliminate certain aspect of the viral genome responsible for disease (such as its capability to replicate). An ideal viral vector would take into account the following: 1) efficient and easy production, 2) alleviate safety concerns, 3) sustained and regulated transgene expression, 4) capable of targeting specific cell types, 5) capable of infecting both mitotic and post-mitotic cells, and 6) able to integrate at specific sites within the targeted cell genome to enable repairs of the defective gene (3-4).

The general principle common to all viral vector systems consist of (1) the removal of most genes coding for viral proteins, especially those that are pathogenic, (2) maintenance of the cis-acting sequences of the viral genome required for viral replication, and (3) expressing the viral replication proteins in packaging cells (6). The gene of interest is integrated into a viral vector cassette and is delivered into packaging cells where the viral replication proteins are expressed. This produces viral particles with the transgene incorporated within the viral genome.

Viral vectors can be divided into two type of vectors: integrating and nonintegrating. Integrating viral vectors contain a reverse transcriptase function that allows them to incorporate their genome into targeted cells. Retroviral and adeno-associated 
virus vectors have integrating functions. Non-integrating viral vectors are not capable of integrating their genome into the targeted cells. Adenovirus viral vectors are nonintegrating.

One significant advantage of viral DNA vectors is their extremely high transfection efficiency in a variety of human tissues. Gene expression using viral vectors has been achieved with high transfection efficiencies in tissues such as kidney, heart, muscle, eye and ovary (14). Retroviral vectors are capable of transfecting high populations (45\%-95\%) of primary human endothelial and smooth muscle cells, (a class of cells that are generally extremely difficult to transfect) (14). Despite such impressive statistics for viral gene transfer, there are several concerns over the use of viruses to deliver DNA therapeutics in humans. One of the chief concern is the toxicity of viruses and the potential of generating a strong immune response because of their proteinaceous capsid. In 1999 as a result of the death of patient suffering a lethal immune response to the adenovirus vector used for gene therapeutics, all clinical trials were suspended (14).

Another disadvantage of viral gene vectors is the randomness by integrating vectors. Since there is no control over the exact location of insertion, random gene transfer can generate insertional mutagenesis that may inhibit expression of normal cellular genes or activate oncogenes. Another disadvantage is the limiting size of the expression plasmid that can be incorporate into the viral cassette. The targeted cells can also develop immunity to viral infection and are resistant to repeated infection. The production of viral titers is also very expensive and there are few issues that exist for 
scale up production. These issues must be address in order to further advance the use of viral vectors for gene therapeutics.

1.3. Non-viral systems for the delivery of genetic material

Non-viral systems can circumvent some of the problems associated with viral vectors. Non-viral delivery of DNA/RNA-based therapeutics can be broken down into two categories: delivery of genetic material is facilitated by either (1) physical forces or (2) a synthetic or natural compound.

Non-viral delivery via a synthetic or natural compound relies upon cationic polymers or lipids to form condensed complexes with negatively charged DNA/RNA through electrostatic interactions. The cationic complexes protect the genetic materials and facilitate cellular uptake. The advantages that are provided with a cationic polymer or lipid delivery system includes their ability to be produced at a large scale, their low immunogenic response, the possibility of selected modifications to their structural makeup and the capacity to carry large inserts (8-11). Currently, the transfection efficiency of these cationic vectors is still lower than that of their viral counterparts but the ability to modify the cationic vectors (such as the addition of binding ligands) can steadily improve transfection efficiency. The ideal objective in gene therapy via a systemic approach requires the development of a stable and non-toxic gene vector that can encapsulate genetic material and is also capable of delivering them into specific cell types for therapeutic purposes. 


\subsubsection{Physical forces as a gene delivery method}

Physical forces can be used to create a change in the physiology of the cellular membrane (such as creating holes or defects) to allow for the passage of genetic material. The physical forces that are used to create a transient membrane are local or rapid systemic injection, particle impact, electric pulse, ultrasound, or laser irradiation (7). Techniques such as electroporation, sonoporation, gene gun delivery, needle and jet injection relies upon physical forces to alter the plasma membrane to allow for the uptake of genetic materials. In cancer gene therapeutics, direct injection of free DNA to tumor sites has been shown to produce high levels of gene expression (11). Direct injection is limited to tissues that are easily accessible such as skin and muscle tissues. Systemic delivery via direct injection is unsuitable due to the presence of nucleases in the body's serum (11). Since the scope of this thesis is to develop a novel cationic polymer system, the review of physical techniques will stop here.

\subsubsection{Cationic lipids for gene delivery}

Cationic lipids (also called cytofectin or lipofection reagents) are one group of synthetic vectors that are commonly used in gene delivery. They were first used for gene therapy in 1987 by Felgner et al (11). Since then, numerous cationic lipids have been synthesized and developed for use in gene delivery in cell culture and animals. There are many advantages that are offered by cationic lipids, such as: they are technically simple in design, are easy to formulate, are commercially available, and may be tailored for specific applications. 
Cationic lipids are made up of a cationic head group that is attached to a lipid hydrophobic tail group by a linker. The positively charged head group is necessary for the binding of the negatively charged phosphate groups on nucleic acid. Therefore all cationic lipids are positively charged amphiphile systems. Cationic lipids and DNA complexes are called lipoplex. Cationic lipids can be classify into three different subgroups based upon their different structural characteristics: (1) monovalent aliphatic lipids that are characterized by a single amine in their head moiety, (2) multivalent aliphatic lipids with multiple amine functional groups in their polar head unit, (3) lipids that are cationic cholesterol derivatives (20).

When DNA is mixed with cationic liposomes two possible phase structures are formed, lamellar or inverted hexagonal. The lamellar form is a condensed and globular structure with DNA monolayers sandwiched between cationic lipid bilayers (11). The inverted hexagonal phase structure consists of DNA coated with cationic lipid monolayers arranged on a two-dimensional hexagonal lattice. For transfection application the cationic lipids are generally mixed with helper lipids, such as DOPE (1,2-dioleyl-snglycerol-3-phosphoethanolamine) to promote the conversion from the lamellar phase structure to an inverted hexagonal phase structure which increases transfection efficiency (11).

Lipoplexes have recently been used for the siRNA delivery in in vivo studies. In a recent study, by Liu et al (21), using Lipofectamine 2000 (a commercially available cationic lipid reagent) they were able to deliver hdm2-siRNA to MCF-7 human breast 
cancer cells that were implanted in rats. By silencing hdm2 in the MCF-7 cancer cells, cell apotheosis was increased and caused a decreased in proliferation.

\subsection{Cationic polymer as a gene delivery system}

Synthetic cationic polymers are promising as a tool for gene delivery because of their high level of design flexibility for biomaterial construction. Cationic polymers are capable of binding and condensing DNA into nano-size particles due to an electrostatic interaction between the positive charge group on the polymer and the phosphate group on the DNA backbone. Polymer and DNA complexes are called polyplexes. Polymers can be designed with varying properties by adjusting the molecular weight distribution, degree of cross-linking between the monomers, and also by incorporating targeting ligands in the polymer for targeted delivery. Some commonly used cationic polymers are PEI (polyethylenimine), PLL (Poly(L-lysine)), chitosans, and dendrimers. There are also many disadvantages when working with cationic polymers. When comparing transfection efficiency, cationic polymers are less efficient than viral vectors in gene delivery. Another disadvantage with cationic polymer is the inability to control the molecular weight distribution and dispersities during the production process of synthetic polymers (14).

\subsubsection{Mechanism of action}

A cationic polymer system must be able to accomplish the following things: (1) capable of binding negatively charged DNA and self-assembly into a vesicle, (2) internalization into the targeted cell, (3) facilitate endosomal escape, and (4) unloading of genetic material. Once the genetic material is released into the cytosol of the cell it must 
be capable of bypassing the nuclear envelop and localize to the nucleus in post mitotic cells for gene expression to occur. This can be achieved by incorporating a nuclear localization sequence (NLS) into the plasmid DNA. For dividing cells, incorporating a NLS into the plasmid DNA can increase transfection efficiency but is not necessary for expression since the nuclear envelop is broken down during mitosis.

\subsubsection{DNA binding and the determination of $\mathrm{N} / \mathrm{P}$ ratio}

Cationic polymer must be capable of binding specifically to DNA in order to condense it and be able to deliver it into the cell. Work done by Sunshine et al has shown that the formation of small, positively charged nanoparticles is a prerequisite for efficient transfection (13). Since polymer mediated gene deliver is based on the electrostatic interactions of the polycation with the negatively charged phosphate groups of DNA, DNA condensation is therefore a function of the cation-to-anion ratio. For cationic polymers that have amine functional groups, the calculation of the $\mathrm{N} / \mathrm{P}$ ratio (where $\mathrm{N}$ is the moles of nitrogen on the polymer and P is the moles of phosphate in the DNA plasmid) is vital in determining whether a stable polyplex will form with DNA. For one $\mu \mathrm{g}$ of DNA there are $3 \mathrm{nmol}$ of phosphate (17). In a recent study by Varkouhi et al (18), it was found that PDMAEMA (poly(2-(dimethylamino)ethylmethacrylate)), QNPHOS homopolymer ((quaternized poly[3,5-bis(dimethylaminomethylene)-p-hydroxy styrene])), and QNPHOS-PEG block copolymer were able to form complexes with both siRNA and DNA over an N/P range of 0.5 to 16 (18). They also found that polyplex formed at an N/P ratio $\geq 2$ formed nanoparticles that are $\leq 200 \mathrm{~nm}$ in size. The decrease in polyplex size is due to an increased in polymer amount in the formulations. This leads to a formation of a tighter condensed complex. 


\subsubsection{Internalization of cationic polymers}

The general pathway for cationic polymers to move from the extracellular space into the nucleus is not fully understood. There are two possible routes for the movement of extracellular polyplexes into the cytosol: (1) the fusion of cationic polymers with the plasma membrane and (2) endocytosis of the cationic polymer. Endocytosis is a general term for the internalization of extracellular particles (fluids, solutes, macromolecules, etc.) by invagination of the plasma membrane and the formation of the vesicles and vacuoles through membrane fission (16). It is generally perceived that carrier-plasma membrane fusion is the more favorable approach for internalization since it avoids the endosomal compartment and its acidic $\mathrm{pH}$ which results in DNA/RNA degradation. However studies of electron and fluorescence microscopy have shown that the cationic carriers can be detected within intracellular vesicles (11). This can suggest that internalization is a result of endocytosis.

There are multiple endocytic pathways that can be used by cationic polymers to enter the cell. Some of the available pathways are clathrin-mediated endocytosis via coated pits, phagocytosis, and macropinocytosis. It's believed that the predominant way of entry for cationic gene delivery systems is by a non-specific adsorptive endocytosis process followed by the clathrin-coated pit mechanism (11). Cellular uptake of polyplexes can occur by either a caveolae mediated or clathrin-coated pits mechanism.

\subsubsection{Endosomal escape}

Once inside the cell the cationic polymer has to escape the endosomal compartment before it matures to the late endosomal stage. At the late endosomal stage 
the endosome is merged with a lysosome and the cationic polymer and its content is degraded (16). The exact mechanism of endosomal escape is unknown but there are several hypothesis that can explain the process. One possible mechanism for endosomal escape is the proton sponge effect. The proton sponge phenomenon has been observed in certain cationic polymers with a high pH buffering capacity $(11,15)$. During the endosomal maturation process in the cytosol, membrane-bound ATPase proton pumps actively transfer protons from the cytosol into the endosomes. This leads to the acidification of the endosomal compartments and the activation of the hydrolytic enzymes to break down materials within the endosome. Polymers with amine groups will resist the acidification mechanism by protonation. As a result of the protonation effect by the amine group more protons will be pumped in by the ATPase pumps in an attempt to reduce the $\mathrm{pH}$ level. The proton pumping action leads to a passive diffusion of chloride ions through the endosomal membrane, leading to an increase in ion concentration. The increased ion concentration within the endosomal compartment causes an influx of water. Eventually the osmotic pressure within the endosome leads to its rupture and the release of the polymer vesicle.

\subsubsection{Cationic polymers in used}

There are plenty of cationic polymers currently in use. Some of the more notable ones are Poly(ethyleneimine), Poly(L-Lysine), chitosan, and dendrimers.

\subsubsection{Poly(ethyleneimine) (PEI)}

Among the various available synthetic polymers available for gene delivery, PEIs, are the most wildly used due to its high nucleic acid condensing capability, ability for 
endosomal escape and nuclear localization abilities (28). PEI can be synthesized for different lengths and can either be branched or linear. They can undergo functionalized group substitution or addition and are a very versatile polymer. PEI polymers can successfully bind and condense DNA molecules to form a homogenous spherical particle due to their high positive charge density. High MW PEIs are very efficient at gene delivery but are also very toxic due to their high positive charge density, whereas, low MW PEIs are less toxic than high MW PEIsbut are not as efficient for gene delivery $(7,9,11,14,28)$. PEIs have a large amount of non-protonated amines with different pKA values on their polymer backbone. This leads to PEIs having a large $\mathrm{pH}$ buffering capacity, which facilitates rapid endosomal escape via the proton sponge effect. Due to their non-biodegradability and high amount of positive charge, PEIs are highly toxic in vivo.

\subsubsection{Poly(L-lysine) (PLL)}

PLL is a biodegradable polymer. High molecular weight PLL is more suitable for gene delivery via systemic injection $(11,14)$. Cationic PLL interacts with anionic DNA molecules to form a positively charged complex that can interact with a negatively charged cell surface to undergo rapid internalization. PLL has a low level of transfection efficiency when compared to PEI because it lacks a way for rapid release from the endosomal compartment. PLL is immunogenic and toxic due to its amino acid backbone. A degradable PLL analogue, poly(a-[4-amino-butyl]-L-glycolic acid) (PAGA) showed significantly higher transfection efficiency than PLL and had no detectable cytotoxicity issues. 
Guo et al (29) has shown that PEGylated cholic acid modified PLL was capable of systemic delivery of siRNA to suppress prostate cancer cells in mice. The PLL was chemically modified with cholic acid on one side of the polymer backbone and subsequently grafted with poly(ethylene glycol) on the other side via a benzoic imine (28). This novel PLL structure is capable of forming cationic micelles that contain a hydrophobic core where water-insoluble molecules can be encapsulated and a hydrophilic surface where nucleic acid can be complexed.

\subsubsection{Chitosan}

Chitosan is a biodegradable and biocompatible linear aminopolysaccharide that is a copolymer made up of 1,4 linked N-acetyl-D-glucosamine and D-glucosamine subunits $(11,14,30)$. Chitosan is formed by the alkaline deacetylation of chitin, which is a polysaccharide found in the exoskeleton of crustaceans. It is a good candidate for a gene delivery system because positively charged chitosan can complex and bind DNA effectively. It is a possible alternative to PEI due to its lower cytotoxicity. When chitosan is complex with pDNA, it forms stable, small nanoparticles ranging from 20-500 $\mathrm{nm}$. Chitosan provides protection against DNase degradation that is comparable to PEI, however the transfection efficiency is lower than that of PEI. In a study, by Hu et al (31), tumor growth was suppressed with amphiphilic stearic acid-g-oligosaccharide (CSOSA) that was conjugated with PEI.

\subsubsection{Dendrimers}

Dendrimers are spherical, highly branched polymers. Dendrimers have a unique, hierarchical, three-dimensional structure. This 3D spherical structure offers synthesis 
control of the molecule in terms of degree and generation of branching. This control can produce polymer particles with a very low degree of polydispersity. This low polydispersity can lead to reproducible gene delivery and a clinically reliable formulation. The most commonly used dendrimers are polyamidoamine (PAMAM) because of its high transfection efficiency. Two commercially available dendrimer formulations that are currently in use for in vitro gene delivery are Superfect and Polyfect.

1.5. Novel polymer: poly(PEG-dodecanoate) (PEGD)

There has been an increase in interest towards the development of synthetic polymers for applications in gene therapy. With synthetic polymers we can modify the backbone to improve efficiency or to incorporate a targeting ligand for specific cell types for targeted gene delivery by a systemic approach. In our lab we have formed a novel polymer of (poly(polyethylene glycol-dodecanoate)) (PEGD). PEGD is a polyester of PEG and dodecanedioic acid (see Figure 1). Formation of the polymer is through ester bonds and degradation occurs by hydrolysis. PEGD is a linear viscous polymer. PEGD is formed by mixing PEG and dedcanedioc acid at a 1:1 molar ratio and heating at $120^{\circ} \mathrm{C}$ for 1-3 days. After the $3^{\text {rd }}$ day the polymer is completely cured.

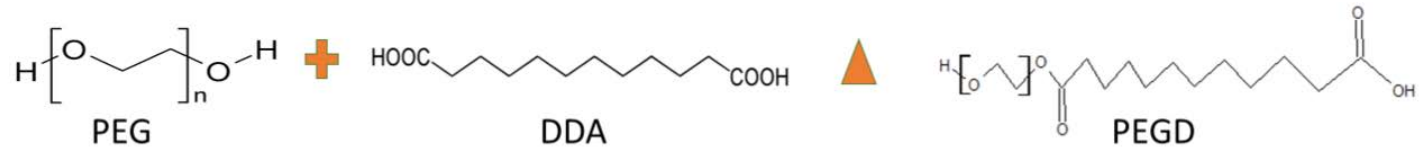

Figure 1. PEGD polycondensation reaction of PEG and DDA monomers. 


\subsubsection{Polyethylene glycol (PEG)}

Polyethylene glycol (PEG) is a polyether compound with many applications from industrial manufacturing to medicine. PEG has very low toxicity, immunogenicity and antigenicity (19). PEG is known to be non-biodegradable but it is readily excretable after administration into living organisms. PEG can be covalently attached to a therapeutic drug or compound as a way to mask it from the immune system.

\subsubsection{Dodecanedioic acid (DDA)}

Dodecanedioic acid is a white solid with a slight odor. At 20 degree Celsius the relative density is 1.172 which is slightly higher than that of water. It has a melting point of 128 degree $\mathrm{C}$ and a boiling point of 250 degree Celsius. It is biodegradable, biocompatible and has a low bioaccumulation potential. It is not known to be mutagenic, genotoxic, or carcinogenic. It can be metabolize to provide energy through fatty acid oxidation (22). DDA has a long hydrocarbon chain and an increase in DDA polymer composition leads to an increase in hydrophobicity.

\subsubsection{Furmaric acid}

Furmaric acid, also known as fumarate, trans-Butenedioic acid, allomaelic acid, and boletic acid, has a molecular formula of $\mathrm{C}_{4} \mathrm{H}_{4} \mathrm{O}_{4}$. It has a molecular weight of 116.1. Furmaric acid is used in oral pharmaceutical formulations and food products and is generally regarded as relatively nontoxic. It has an internal alkene group between Carbon 2 and Carbon 3. 


\subsubsection{Itaconic acid}

Itaconic acid is also known as butanedioic acid. It has a molecular formula of $\mathrm{C}_{5} \mathrm{H}_{6} \mathrm{O}_{4}$. It has a molecular weight of 130.1 . It is non-toxic and is readily biodegradable. It has a terminal alkene group at Carbon 2.

\subsubsection{Addition of FA and IA to PEGD backbone}

PEGD polymers can be further modified to incorporate a double bond in the polymer backbone by the addition of either furmaric acid (FA) or itaconic acid (IA) during the polycondensation reaction. Varying the ratio of FA/IA to DDA would lead to a change in the hydrophobicity. Higher concentration of DDA would lead to a more hydrophobic polymer due to the long hydrocarbon chain on DDA.

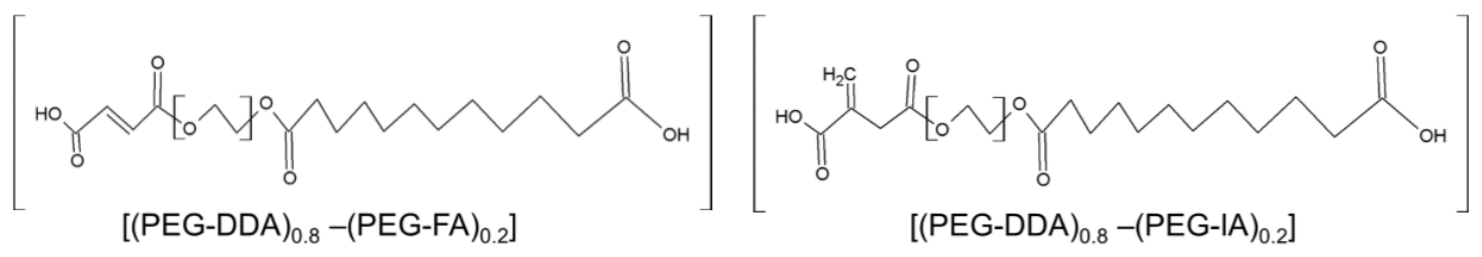

Figure 2. PEGDF and PEGDI polymers.

\subsubsection{Cys-(Arg)n}

Cys-(Arg)n is a peptide that can be synthesis with the use of 1,1'-

Carbonyldiimidazole (CDI). The Cys-(Arg)n peptide will have a Cysteine head and an Arginine tail. Cysteine and Arginine are both semi essential amino acids. The thiol side chain on Cysteine can serve as nucleophile in chemical reactions. Every Arginine residue 
has four nitrogen atom and in a Cys-(Arg) ${ }_{n}$ where $n=8$, there is a total of 32 total nitrogen atoms. This will contribute greatly to the positive charge density of the peptide chain.

\subsection{HEK 293 Cells}

HEK293 (human embryonic kidney) cells are a cell line that has been extensively used as an expression tool for recombinant proteins. Graham et al transformed the human embryonic kidney cells after exposing them to sheared fragments of human adenovirus type 5 (Ad5) (25). The introduction of foreign plasmid vectors (especially those with a cytomegalovirus (CMV) promoter) can effectively hijack the cells protein machinery and force the translation of gene products that were artificially incorporated into the plasmid vector. Although of epithelial origin, HEK293 cell's biochemical machinery is capable of generating functional protein from a wide spectrum of both mammalian and nonmammalian nucleic acids (25). HEK293 can also be stably transformed to express protein units that are not native to its cellular makeup. They serve as a powerful tool for transient gene expression studies.

\subsection{Alamar Blue Cytotoxicity}

Cell health can be monitored by numerous methods from plasma membrane integrity, DNA synthesis, DNA content, enzyme activity, and cellular reducing conditions, known indicators of cell viability and cell death (33). Alamar Blue (Thermo Scientific) is a cell heath indicator that measures the reducing power of living cells to quantitatively measure the proliferation of various human and cell lines. Healthy cells maintain a reducing environment within the cytosol of the cell. The active ingredient in Alamar Blue is Resazurin, a non-toxic cell permeable compound that is blue in color and 
virtually non-fluorescent. Resazurin is reduced to resorufin (a red and highly fluorescent compound) in healthy cells. By measuring the fluorescent intensity of cells exposed to resazurin, we can quantitatively determine their viability. 


\section{CHAPTER 2: STATEMENTS AND SPECIFIC AIMS}

\subsection{Statement of purpose}

From the described characteristic of PEGD it is believed that it may be a good candidate for use as a gene delivery vector. Modification of PEGD is needed to make it viable for binding DNA. PEGD in its unmodified form has no cationic charge, therefore we will need to find a way to incorporate a positive charge to the PEGD polymer backbone to allow for polymer/DNA electrostatic interaction. We can do this in a twostep process. First, we can introduce an alkene group onto the PEGD polymer backbone by adding either furmaric acid or itaconic acid and adjusting the ratio of furmaric acid or itaconic acid to DDA during PEGD synthesis. Second, we can perform a Michael Addition Reaction to bind a cationic ligand to the alkenes located on the furmaric/itaconic acid monomers throughout the polymer backbone. Some possible ligands that can be used are protamine sulfate and Cys-(Arg)n.

The scope of this thesis is to test whether or not the modified PEGD polymer will be suitable for gene transfection. If the PEGD polymer is capable of transfection then it will be a novel polymer base gene delivery system. It is believed that PEGD modified with Cys-(Arg) $)_{n}$ will be able to condense DNA effectively and be capable of transporting it into the cell for transfection.

\subsection{Specific Aims}

Aim 1, to synthesize PEGD modified with an 80:20 ratio of DDA to either furmaric acid or itaconic acid. This modified PEGD will be further modified by binding a cationic 
ligand (such as protamine sulfate or Cys-(Arg)n) to the double bond of the furmaric acid or itaconic acid monomer. To also characterize the modified PEGD polymer by Raman spectroscopy, gel permeation chromatography (GPC), and dynamic light scattering (DLS).

Aim 2, to determine if modified PEGDF/I polymers are capable of binding DNA, transfect HEK 293 cells and their effects on cellular viability. 


\section{CHAPTER 3 METHODLOGY}

\subsection{Synthesizing polymer}

\subsubsection{Preparation of PEGDF and PEGDI polymers}

Polyethylene glycol (PEG, MW 202), fumaric acid (FA, mw 116.07), itaconic acid (IA, mw 130.1), dodecanedioc acid (DDA, MW 232.2) were purchased from Sigma Aldrich. PEGDF and PEDGI will be prepared by mixing PEG and DDA/furmaric acid or itaconic acid at a 1:1 ratio. The ratio of DDA to furmaric acid or itaconic acid are 80:20. The mixture will be heated at 120 degrees Celsius. PEG DDA/furmaric acid or itaconic acid is polymerizing due to ester bond formation. Polymer samples will be collected at 24 hrs and 48 hrs to acquire different MW distribution.

\subsubsection{Acquiring of Cys-(Arg)s and protamine sulfate}

Cys-(Arg)8 (CA, 5 mg white powder) was purchased commercially from Biomatik. The sequence ordered was Cys-Arg. The molecular formula is $\mathrm{C}_{78} \mathrm{H}_{123} \mathrm{~N}_{35} \mathrm{O}_{14} \mathrm{~S}$ with a MW of 1783.11. Protamine sulfate (PS) was purchased from Sigma-Aldrich.

\subsubsection{Modification of PEGDF and PEGDI with Cys-(Arg)8 and Protamine Sulfate}

PEGDF and PEGDI were modified with Cys-(Arg)8 and Protamine sulfate via the Michael addition reaction. Michael addition reaction is a nucleophile addition to an $\alpha, \beta-$ unsaturated carbonyl compound. The thiol Michael addition reaction rates increase with $\mathrm{pH}$ (23). For protamine sulfate modification, a $2 \%$ solution of PS was made with DI 
water (Lab source). $20 \mu \mathrm{g}$ of $48 \mathrm{hr}$ polymer sample of PEGDF and PEGDI was mixed with $100 \mu \mathrm{l}$ of the $2 \%$ PS solution. The samples were incubated at 37 degrees $C$ for $3 \mathrm{hrs}$. For modification with Cys-(Arg)8, $1 \mathrm{mg}$ vial of CA was dissolved in $1 \mathrm{ml}$ of PBS, $\mathrm{pH}$, for a 1mg/ml solution. $20 \mu \mathrm{g}$ of day 2 sample of PEGDF and PEGDI was mixed with 200 $\mu 1$ of $1 \mathrm{mg} / \mathrm{ml}$ solution of $\mathrm{CA}$ and incubated at $37^{\circ} \mathrm{C}$ for $3 \mathrm{hrs}$.

\subsection{Characterization of the Polymer}

\subsubsection{Raman Spectroscopy}

Raman Spectroscopy is a spectroscopic technique that is used to observe vibrational, rotational, and other low-frequency modes in a system. It is based upon the inelastic scattering of radiation (usually in the visible or near-infrared region). It relies on the inelastic or Raman scattering of monochromatic light (a laser). The laser interacts with the molecular vibrations, phonons, or other excitations in the system. This interaction results in the energy of the laser photons being shifted up or down and the shift in energy gives information about the vibration modes in the system. We will be using Raman Spectroscopy to determine if the Michael addition of Cys-(Arg)8 and Protamine Sulfate to the polymer was successfully. The absence of a strong peak at around $\sim 1600 \mathrm{~cm}^{-1}$ would signify that bonding has occurred between the amine and the thiol to the alkene of the polymer backbone.

Raman spectra was taken with Raman Micro 400 Series Raman Spectroscopy (Perkin Elmer) using a 50X objective lens and with a 2 to 4 second exposure time. These spectrum data were used to evaluate the polymerization process and the chemical 
structure of PEGDF and PEGDI pre and post modification. Samples were pipette onto the shiny side of an aluminum foil and microscope slides.

\subsubsection{Gel Permeation Chromatography}

Gel permeation chromatography (GPC) is a size exclusion chromatography that separates analytes on the basis of size. GPC was carried out on the Prominence GPC System. 2 mg of polymer sample were dissolved in tetrahydrofuran (THF).

\subsubsection{Dynamic Light Scattering (DLS)}

Modified PEGDF and PEGDI polymers size were measured by dynamic light scattering (DLS) using a Malvern Zetasizer (Malvern Instruments, Worcestershire, United Kingdom). Size measurements were taken at $25^{\circ} \mathrm{C}$ using a 1:30 (vol/vol) dilution of the modified polymer suspension and GFP plasmid in deionized (DI) water. The polydispersity index (PDI) was used as a measure of particle size distribution.

\subsection{Determination of modified PEGD transfection capabilities}

\subsubsection{Determination of modified PEGDF and PEGDI binding capabilities}

Cationic polymers must be capable of binding specifically to DNA in order to condense it and be able to deliver it into the cell. The purpose of this experiment is to be able to quickly test whether the cationic formulation will function as a viable gene delivery vehicle. The binding assay was conducted and checked via gel electrophoresis. Modified PEGDF and PEGDI polymers will be allowed to complex with DNA for 30 minutes at RT. They will then be loaded on a 1\% agarose gel and allowed to run at $100 \mathrm{~V}$ for 45 minutes in TAE buffer. The agarose gel will then be stained with Sybr Green (a 
nucleic acid dye) for 40 minutes. The agarose gel will then fluoresce by blue light and a Nikon 35mm DLS is used to capture a picture of the gel at 3200 ISO (light sensitivity of the camera, higher ISO leads to an increase in light sensitivity) with 4 sec exposure.

\subsubsection{Culturing of HEK 293 Cells}

Human Embryonic Kidney 293 cells (HEK 293) were generously provided by Tatiana Slepak of the LemBix Lab (Miami Project Cure for Paralysis, University of Miami). HEK 293 cells were maintained with Dulbecco’s Modified Eagle Medium: Nutrient Mixture F-12 (DMEM/F12) with 10\% fetal bovine serum (FBS) and incubated at $37^{\circ} \mathrm{C}$ with $5 \% \mathrm{CO} 2$. Media was changed every 3 days and cells were passed when confluency was $~ 90 \%$ with trypsin $+0.05 \%$ EDTA

\subsubsection{Cell viability via Alamar Blue Assay}

Cell viability will be determined by an Alamar Blue Assay (ThermoFisher Scientific) which measures cell health by their ability to reduce resazurin (the active component in Alamar Blue) into resorufin (a compound that is red in color and highly fluorescent) (28). 15,000 HEK293 cells were plated in a 12 well plate. A 10\% Alamar Blue solution was made with DMEN/F12 culture medium. Cells were incubated with Alamar Blue solution for $4 \mathrm{hrs}$ at $37^{\circ} \mathrm{C}$. Three $100 \mu \mathrm{l}$ samples per group $(\mathrm{n}=3)$ were gathered at day 0 (prior to incubation with modified polymers), day 1, day 2, and day 4 for each group. Samples were measured for fluorescence intensity to determine cell viability. 


\subsubsection{Transfection study in HEK 293 Cells}

PEGDF and PEGDI modified with PS and CA are tested to determine if transfection will occur in HEK 293 Cells. HEK 293 cells will be transfected with pTurboGFP. If transfection is successful then expression of GFP will be seen when the cells are exposed to light in the blue to ultraviolet range. Transfected cells will exhibit a bright green fluorescence.

HEK 293 cells will be plated in 35 mm culture dishes. The total amount of cells per plate will be $~ 50,000$ cells. Modified PPEGDF and PPEGDI will be allowed to complex with pGFP for 30 minutes prior to transfection. Polymer/DNA solution will be added drop wise to the HEK293 cells. After 4 hours the media will be change and cells will be visualize at $24 \mathrm{hrs}, 48 \mathrm{hrs}$, and $72 \mathrm{hrs}$. Pictures will be taken of the transfected cells.

\subsubsection{Transfection efficiency}

Cell Profiler is a free, open-source software designed to quantitatively measure phenotypes from images. It is capable of quantifying the transfection expression rate amongst the different modified polymers. From this information transfection efficiency can be determine and compared between the different polymers samples used. Cell profile requires establishing proper pipelines for data analysis and proper imaging modules using the right algorithms to help filter out noise and identify the proper object of interest (such as cell count and transfected cells). 
Images were taken $24 \mathrm{hr}$ post transfection of HEK 293 cells. A total of 20 images were taken per group (10 bright field and 10 fluorescence). Images were loaded into Cell Profiler and a pipeline of image modules were used to filter the images and identify the objects of interest within the images (such as transfected and non-transfected cells).

\subsection{Statistical Analysis}

Statistical significance was identified by one-way ANOVA (SPSS, Chicago, Illinois) for the difference among treatment and control groups. A p-value $<0.05$ was considered to be statistically significant. 


\section{CHAPTER 4 RESULTS}

\subsection{Results accomplished for Specific Aim 1}

\subsubsection{Raman Spectra of PEGDI/F Polymers}

The Raman spectra of both PEGDF and PEGDI shows peaks at $1735 \mathrm{~cm}^{-1}$ indicating the appearance of typical ester bonds, which is an indicator of polymer formation by esterification or the formation of ester bonds (Figure 3). Also peaks at 1655 $\mathrm{cm}^{-1}$ indicates the presence of a carbon-carbon double bond, a necessary component for polymer modification by the Michael addition reaction.

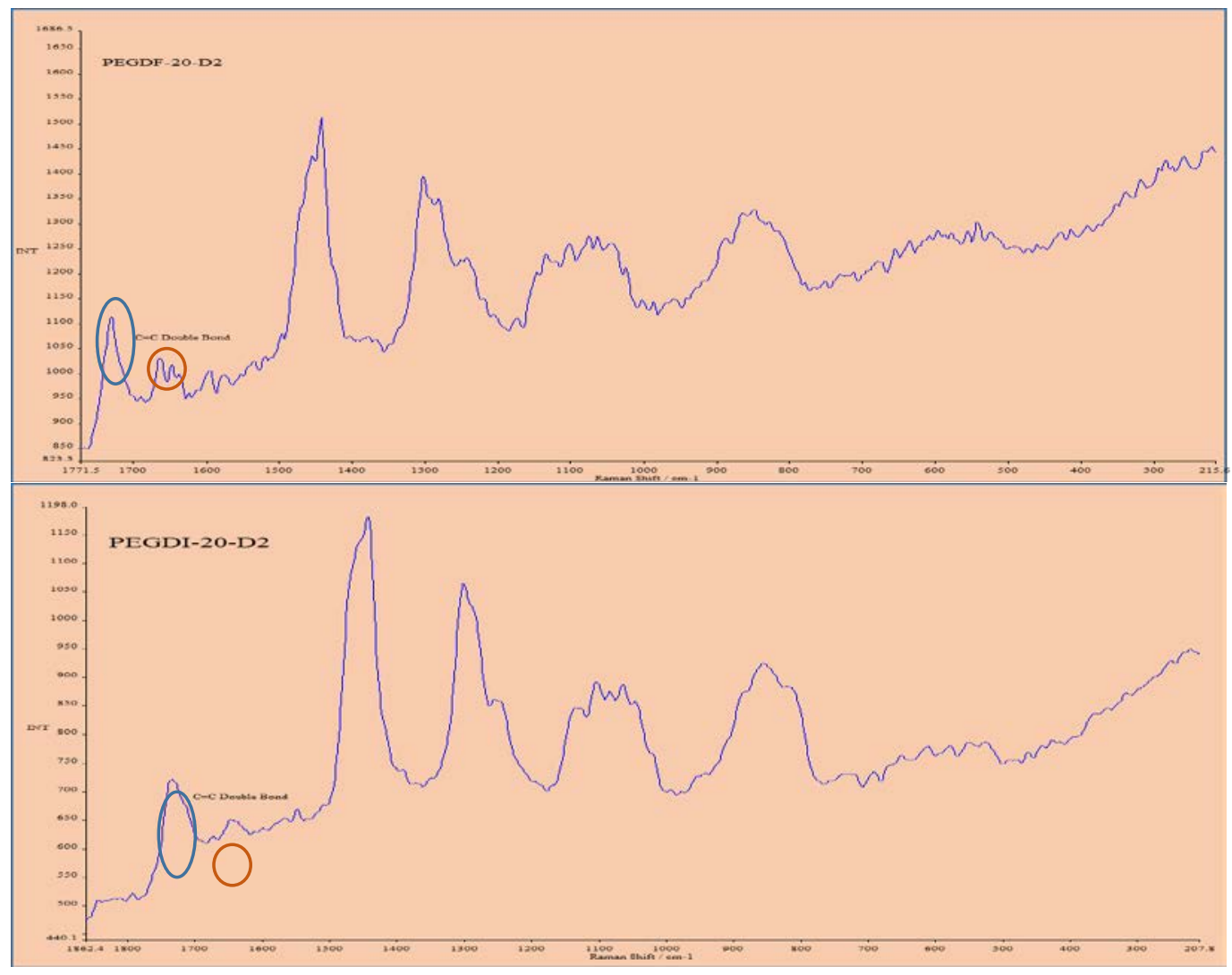

Figure 3. Raman spectrum of PEGDF and PEGDI Polymers shows peaks at $1735 \mathrm{~cm}^{-}$ ${ }^{1}$ (blue circle) and $1655 \mathrm{~cm}^{-1}$ (red circle) indicating the presence of ester bonds and carbon-carbon double bonds, respectively. 


\subsubsection{Dynamic Light Scattering of modified PEGDF/I Polymers}

The mean size for dynamic light scattering (DLS) data gives us modified cationic polymers (CPs) and DNA polyplexes sizes that ranges from 130 to $170 \mathrm{~nm}$ (see table 1 and figure 4). Commercially bought JetPEI was able to condense DNA and form polyplexes with diameters of around $80 \mathrm{~nm}$. The polydispersity (PDI) values measured for modified CPs/DNA polyplexes were around 0.8 which signifies the polyplex solution contains large aggregates and or sedimentation. From the DLS readings there were instances of two peaks showing different diameter values: a large value (>1500 nm) and a smaller value $(\sim 160 \mathrm{~nm})$. The larger peaks had a smaller intensity $(<10 \%)$. There was a statistically significant difference in polyplex size between groups as determined by oneway ANOVA $(F(4,14)=33.957, \mathrm{p}<0.0001)$. A Tukey post-hoc test showed that there is a difference in polyplex size between PEGDF+PS ( $<<0.00001)$, PEGDI+PS $(\mathrm{p}<0.00001)$, PEGDF+CA $(p<0.00001)$, and PEGDI+CA $(p<0.0007)$ when compared with JetPEI polyplexes.

\begin{tabular}{|l|c|c|}
\hline \multicolumn{1}{|c}{ Formulation } & Size $(\mathrm{nm}$ (SD) & Polydispersity (PDI) (SD) \\
\hline PEGDF+PS/DNA PolyPlex & $171.7 \pm 15$ & $0.78 \pm 0.05$ \\
PEGDI+PS/DNA Polyplex & $161.3 \pm 13.7$ & $0.79 \pm 0.001$ \\
PEGDF+CA/DNA Polyplex & $161.3 \pm 5.5$ & $0.8 \pm 0.05$ \\
PEGDI+CA/DNA Polyplex & $136 \pm 12$ & $0.785 \pm 0.002$ \\
JetPEI/DNA Polyplex & $78 \pm 7$ & $0.214 \pm 0.01$ \\
\hline
\end{tabular}

Table 1. Mean size and PDI values for modified PEGDF and PEGDI polymers $(n=3)$. There was a statistical difference between modified PEGDF/I polymers and JetPEI polyplex sizes $(p<0.0001)$. 


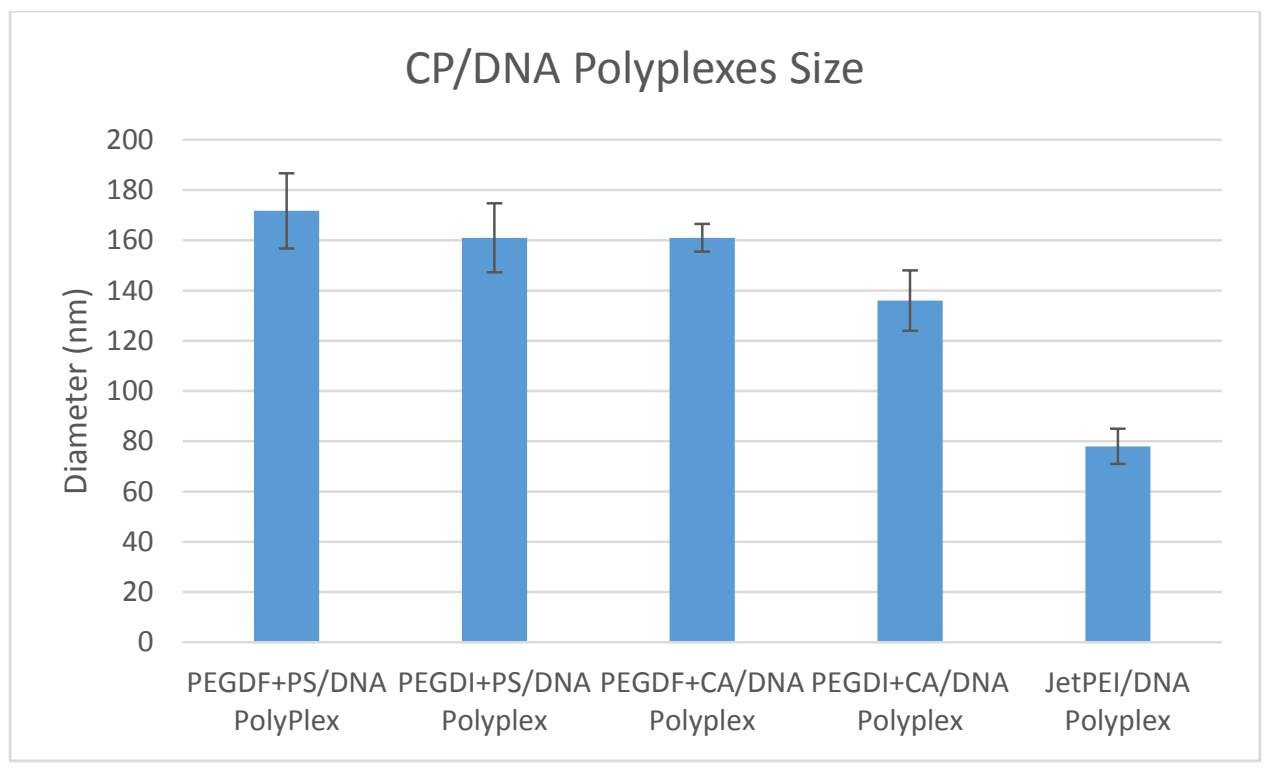

Figure 4. Mean size of modified PEGDF and PEGDI polymers $(n=3)$. Error bars are SD. There was a statistical difference between modified PEGDF/I polymers and JetPEI polyplex sizes $(p<0.0001)$.

\subsubsection{GPC of PEGDF/PEGDI polymers}

The MWs measured by GPC column of PEGDF and PEGDI are listed in Table 1. The increase in MW shows an elongation of polymers by esterification-the longer the reaction was allowed to run. Polymer samples that were taken after 24 hrs have a MW of 1552 Da and 1334 Da for PEGDF and PEGDI, respectively. After 48 hrs of reaction, the polymers MW increased by 1000 Das.

\begin{tabular}{|l|c|c|c|c|}
\hline & \multicolumn{2}{|c|}{24} & \multicolumn{2}{c|}{48} \\
\hline Formulation & MW & MN & MW & MN \\
\hline PEGDF & 1552 & 1016 & 2995 & 1576 \\
\hline PEGDI & 1334 & 924 & 2561 & 1483 \\
\hline
\end{tabular}

Table 2. GPC measurements of PEGDF and PEGDI polymers. The increase in polymer MW shows polymer elongation occurring by esterification. 

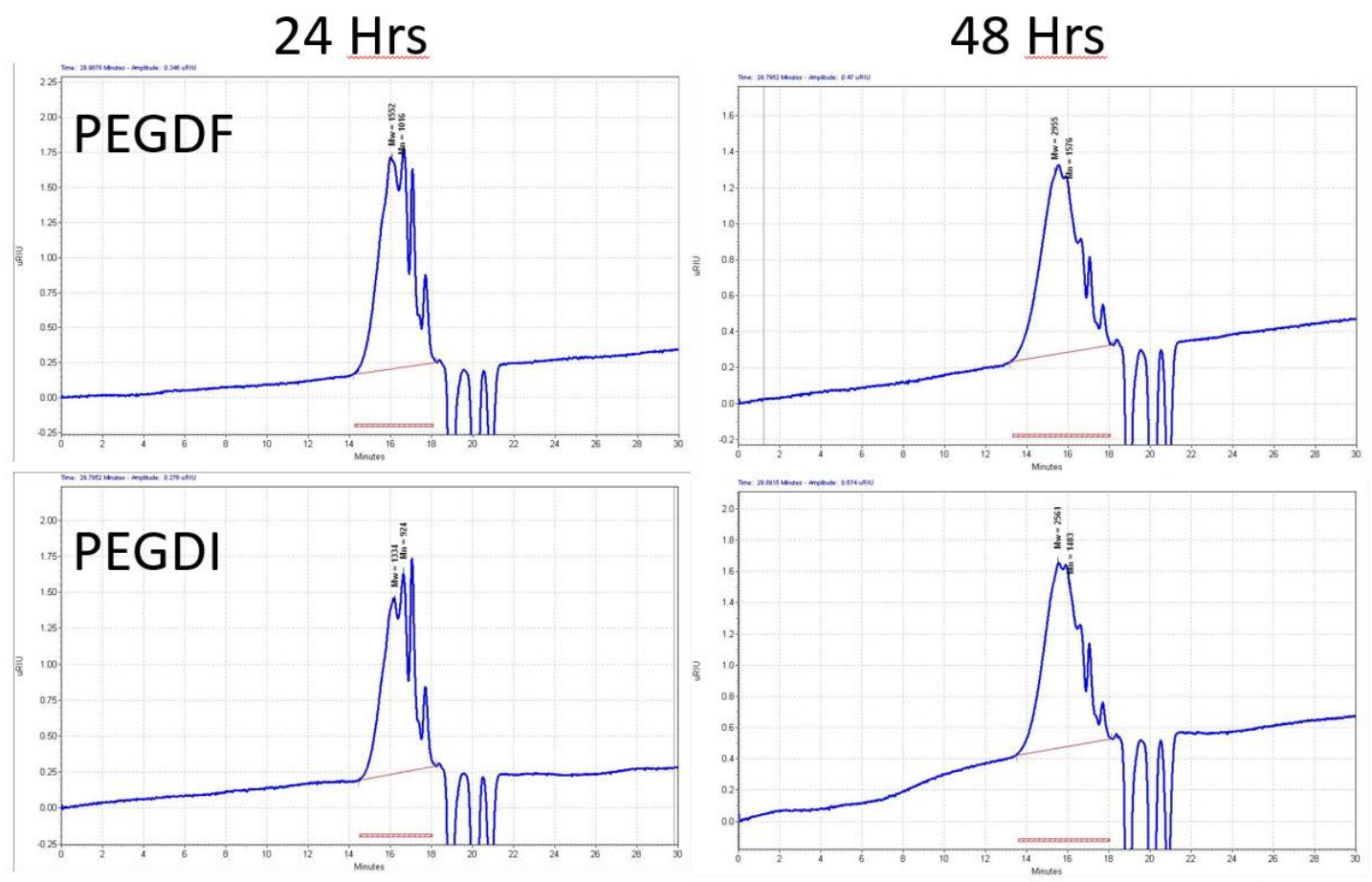

Figure 5. GPC measurements of PEGDF and PEGDI polymers. A change in MW from 24 hrs to 48 hrs showed polymer elongation by esterification.

\subsection{Results accomplished for Specific Aim 2}

\subsubsection{DNA Binding Assay}

PEGDF and PEGDI Polymers modified with protamine sulfate and Cys-Arginine were tested for their binding capabilities through the gel binding assay. Commercially bought JetPEI was used as a positive control and DNA plasmids alone were used as a negative control. The assay showed that all forms of modified PEGDI and PEGDF were capable of binding and condensing DNA (Figure 6) and prevented the migration of GFP plasmid through the agarose gel. The surface charge of PEGDF and PEGDI polymers modified with PS was strong enough to bind bromophenol blue (a negatively charged leading dye) whereas polymers modified with Cys-Arg and JetPEI were unable to bind bromophenol blue. 


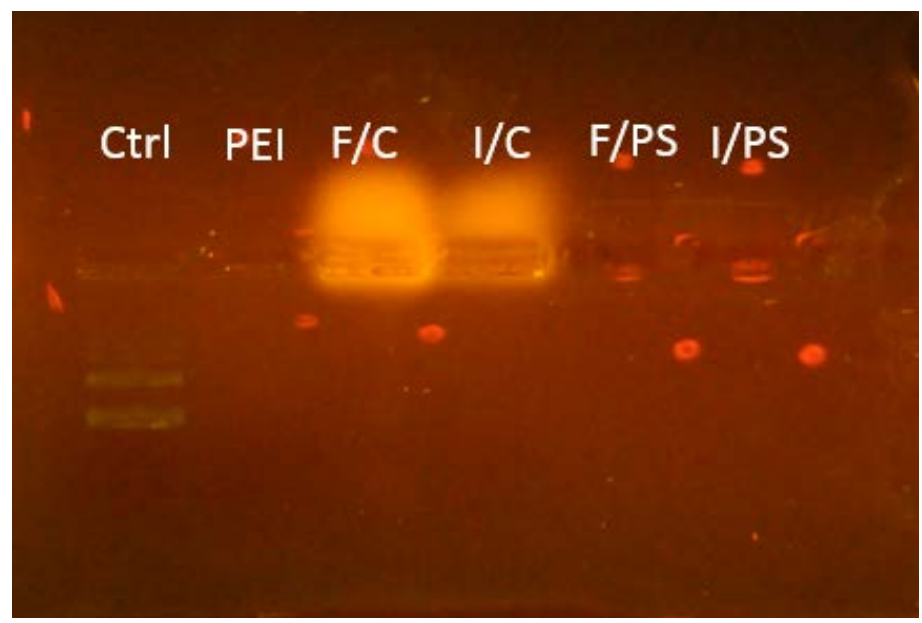

Figure 6. Gel binding assay. PEGDF and PEGDI modified with protamine sulfate (PS) and Cys-Arginine $(C)$ were capable of binding and retarding the migration of GFP plasmid through the agarose gel. pGFP was complexed with the different variations of modified polymers, JetPEI, and nothing(the control). Gel was stained with SybrGreen (a nucleic dye) and fluoresce under a blue LED light. As seen in the figure all of the groups were capable of binding $p G F P$ and prevent its migration through the agarose gel whereas the control (GFP alone) showed the pGFP plasmid migrating through the agarose gel.

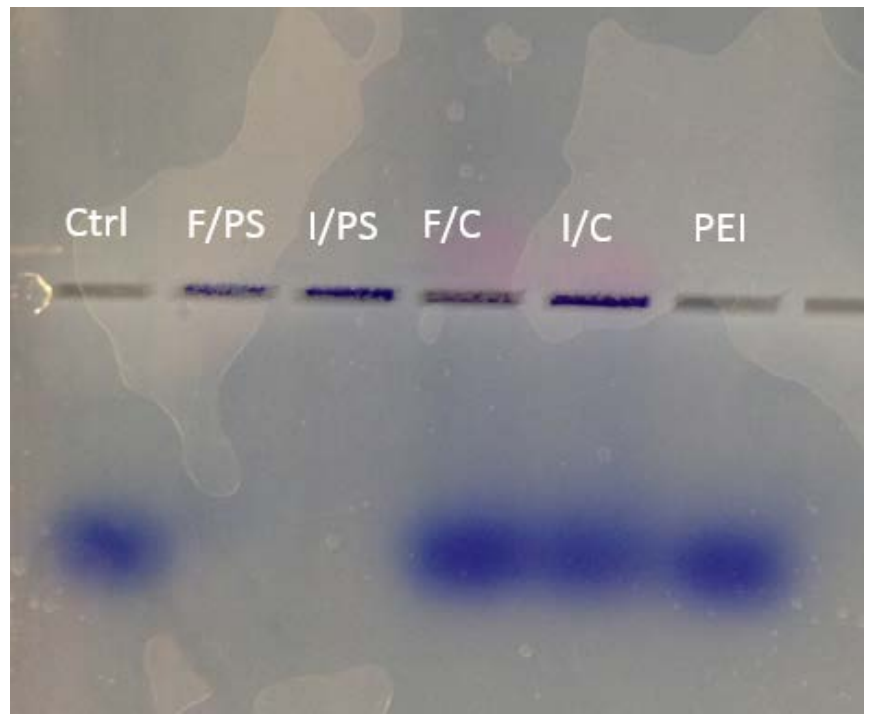

Figure 7. Gel binding assay. Unstained image of agarose gel under normal light. Here you can see that PEGDF/I modified with protamine sulfate (PS) has a high enough surface charge that it was capable of binding bromophenol blue, whereas PEGDF/I polymers modified with Cys-Arg and JetPEI were unable to bind bromophenol blue.

4.2.2 In vitro cytotoxicity analysis of modified PEGDF/I polymers by Alamar blue assay 
PEGDF-PS, PEGDI-PS, PEGDF-CA, PEGDI-CA, and JetPEI were tested for their cytotoxicity with the alamar blue assay. Samples were loaded onto a 96 well plate and the fluorescence intensity values were measured from Day 0 to Day 4 . There was a statistically significant difference in mean intensity value between groups as determined by one-way ANOVA $(F(5,48)=24.637, p<0.001)$. A Tukey post-hoc test showed that there is a difference in mean intensity values between PEGDF-PS $(\mathrm{p}<0.0001)$, PEGDI-PS $(\mathrm{p}<0.0001)$, and JetPEI $(\mathrm{p}<0.0001)$ when compared with the control group, whereas the difference in mean fluorescence between control, PEGDF-CA ( $\mathrm{p}>0.05)$, and PEGDI-CA ( $>0.05$ ) were not significant. This result shows that polymers modified by PS exhibit cytotoxicity whereas polymers modified with CA are not cytotoxic.

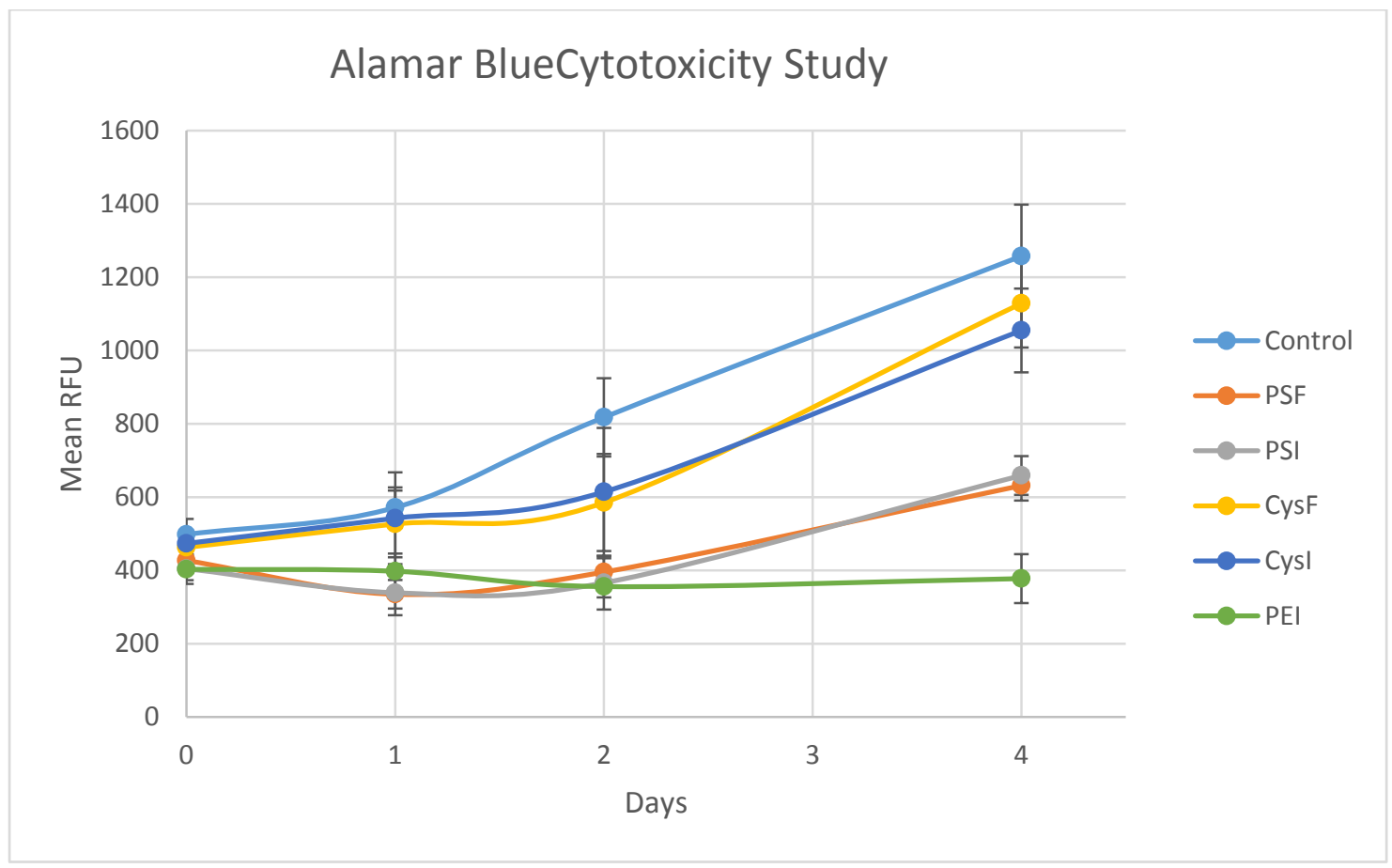


Figure 8. Alamar Blue Assay of modified polymers. Values are given as mean \pm standard deviation. Statistical testing shows that PEGDF-PS, PEGDI-PS, and PEI exhibit cytotoxicity when compared to the control, whereas PEGDF-CA and PEGDI-CA did not exhibit cytotoxicity when compared to the control $(n=9)$.

\subsubsection{Transfection of HEK 293 Cells}

PEGDF-PS, PEGDI-PS, PEGDF-CA, and PEGDI-CA were capable of transfecting HEK293 cells with pTurboGFP with varying success (Figure 8). Visually, we can see a lower cell density in PEI, PEGDF-PS, and PEGDI-PS groups when compared to the control, whereas cell density in PEGDF-CA and PEGDI-CA groups were similar to control group.
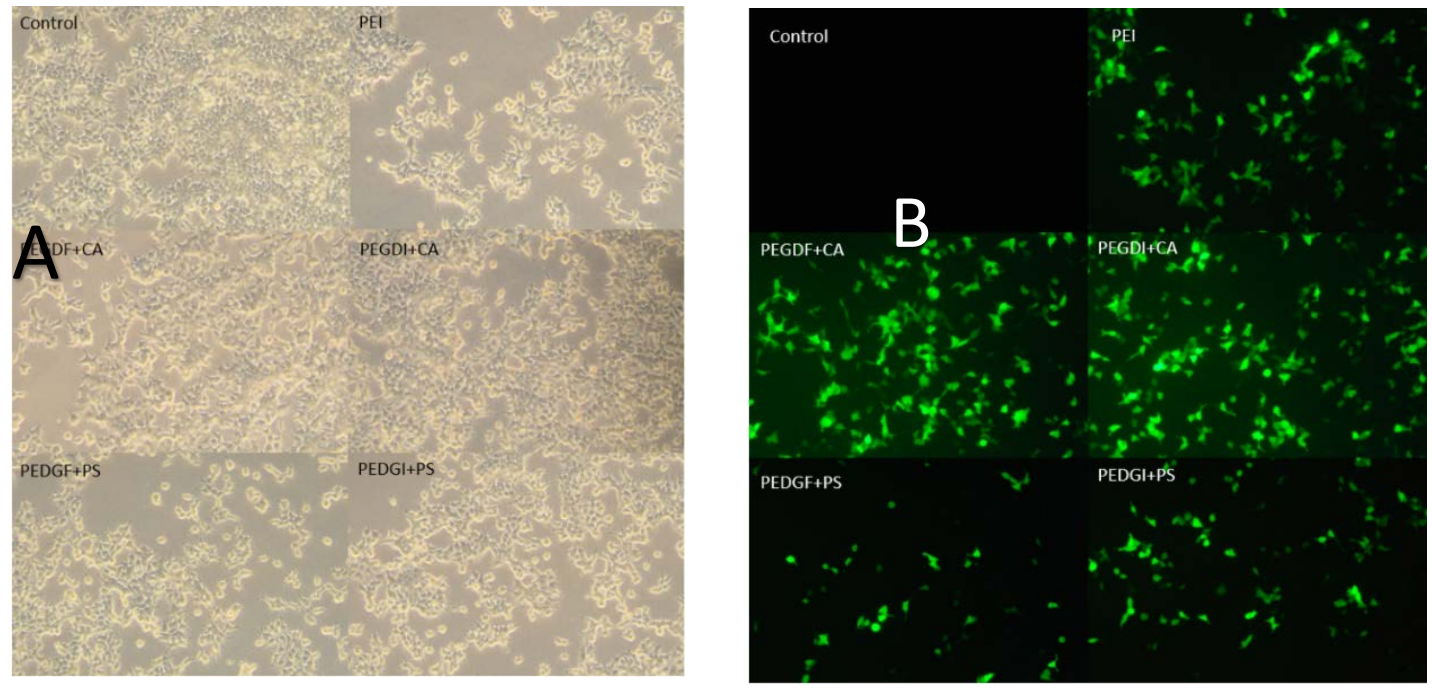

Figure 9. Transfection of HEK293 cells with modified PEGDF and PEGDI Polymers. A. Phase contrast of 24 post transfection. B. Same field fluorescence microscopy of HEK 293 expressing $p$ TurboGFP $(n=3)$.

4.2.4 Cell Profiler image analysis of transfected cells

Cell profiler showed that it was capable of identifying cells based upon the difference in intensity between the foreground (object of interest) and the background (see Figure 9). With the right threshold, the program is able to objectively identify 
important objects and provide a count of the objects of interest. The images captured are a representation of random fields of the culture plate of transfected cells. Cell profiler was used to do a count of total cells in the bright field microscopy and a count of GFP positive cells in fluorescence microscopy images (Figure 9).

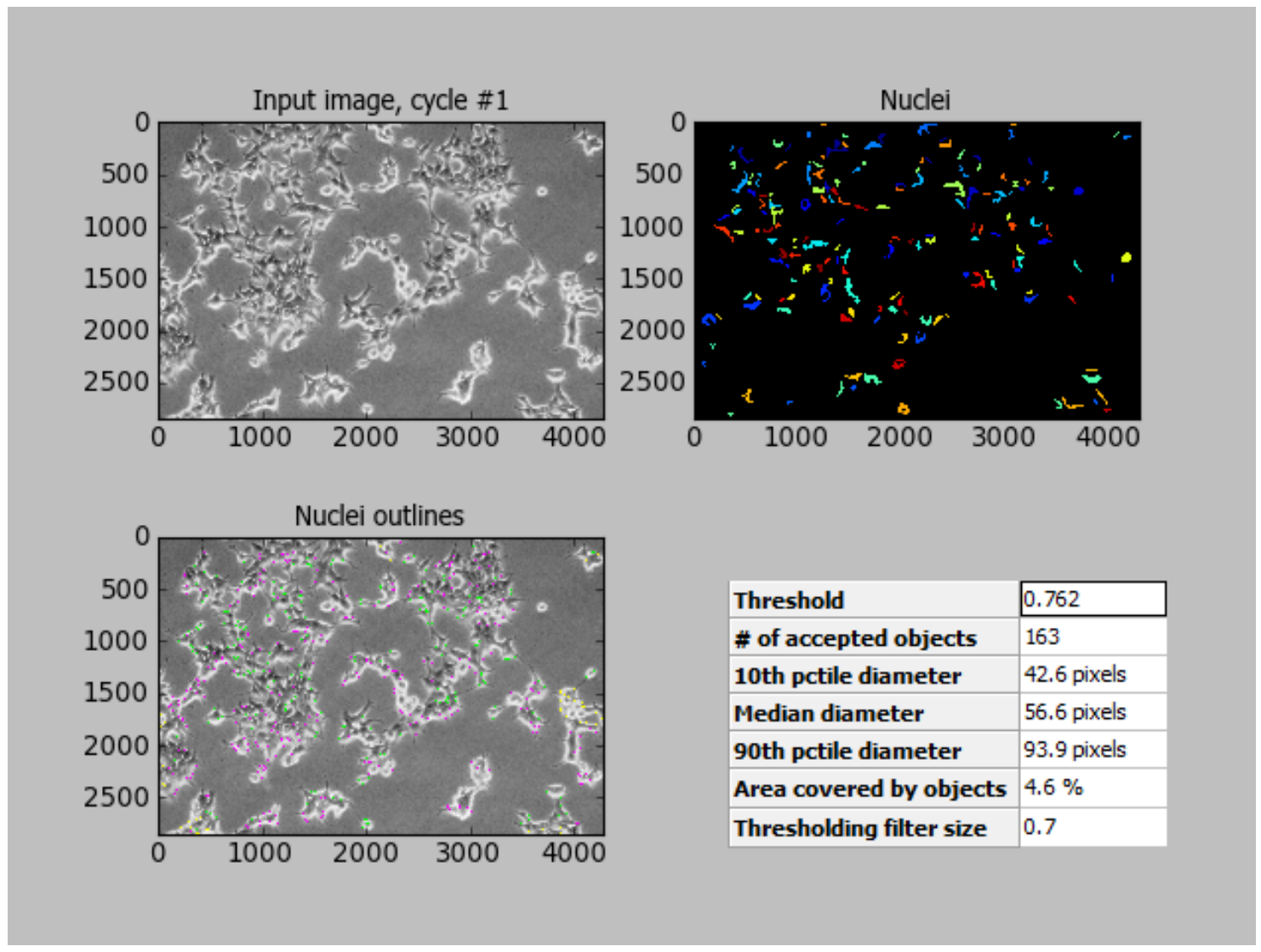

Figure 10. Cell Profiler image analysis of bright-field microscopy images. Threshold values were set to identify HEK293 cells in bright-field images. 


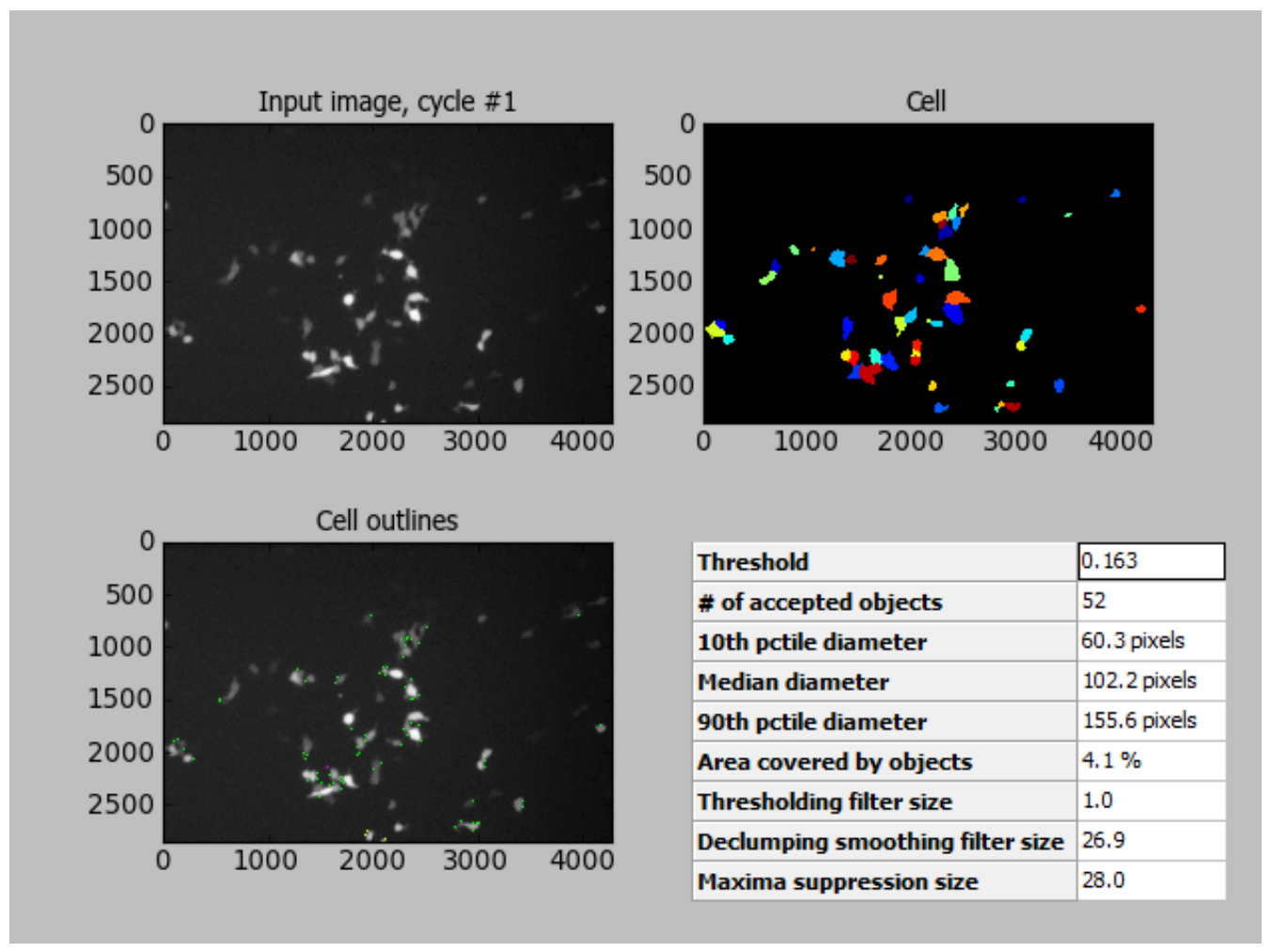

Figure 11. Cell Profiler image analysis of fluorescence microscope images of $24 \mathrm{hr}$ post transfection.

\subsubsection{Transfection efficiency in HEK293 cells}

Transfection efficiency is determine (see Table 3 and Figure 10) by the fraction of transfected cells (GFP positive objects) as a percentage of the total cell count (positive object identification in bright field microscopy). Image analysis using Cell Profiler showed that PEGDF-PS and PEGDI-PS had very low transfection efficiency of around 18\% and 15\%, respectively. PEGDF-CA and PEGDI-CA showed slightly better transfection efficiency of $27.8 \%$ and $30.7 \%$. Commercially bought JetPEI had a transfection efficiency of $45 \%$. There was a statistically significant difference in the transfection efficiency between groups as determined by one-way $\operatorname{ANOVA}(F(5,12)$ $=124.688, p<0.0001)$. Tukey post hoc analysis showed that all of the modified variant 
groups were statistically $(\mathrm{p}<0.0001)$ less efficient than commercially available JetPEI.

Figure 11 provides a graphical representation of non-transfected cells to transfected cells.

\begin{tabular}{|c|c|c|c|}
\hline \multicolumn{4}{|c|}{ HEK293 Cells Transfection } \\
\hline Group & Total Cells & Transfected Cells & Efficiency \\
\hline Control & $2431 \pm 258$ & N/A & N/A \\
JetPEI & $1704 \pm 434$ & $773 \pm 166$ & $45.8 \pm 3.8$ \\
PEGDF+CA & $2353 \pm 446$ & $650 \pm 101$ & $27.8 \pm 2.2$ \\
PEGDI+CA & $2427 \pm 395$ & $744 \pm 127$ & $30.7 \pm 2.3$ \\
PEGDF+PS & $2200 \pm 475$ & $395 \pm 109$ & $17.7 \pm 1.6$ \\
PEGDI+PS & $2318 \pm 401$ & $351 \pm 72$ & $15.2 \pm 2.7$ \\
\hline
\end{tabular}

Table 3. Efficiency of transfection of HEK 293 cells. Values are given as mean \pm standard deviation and were tabulated from Cell Profiler image analysis of $24 \mathrm{hr}$ post transfection images of HEK 293 transfection experiments $(n=3)$.

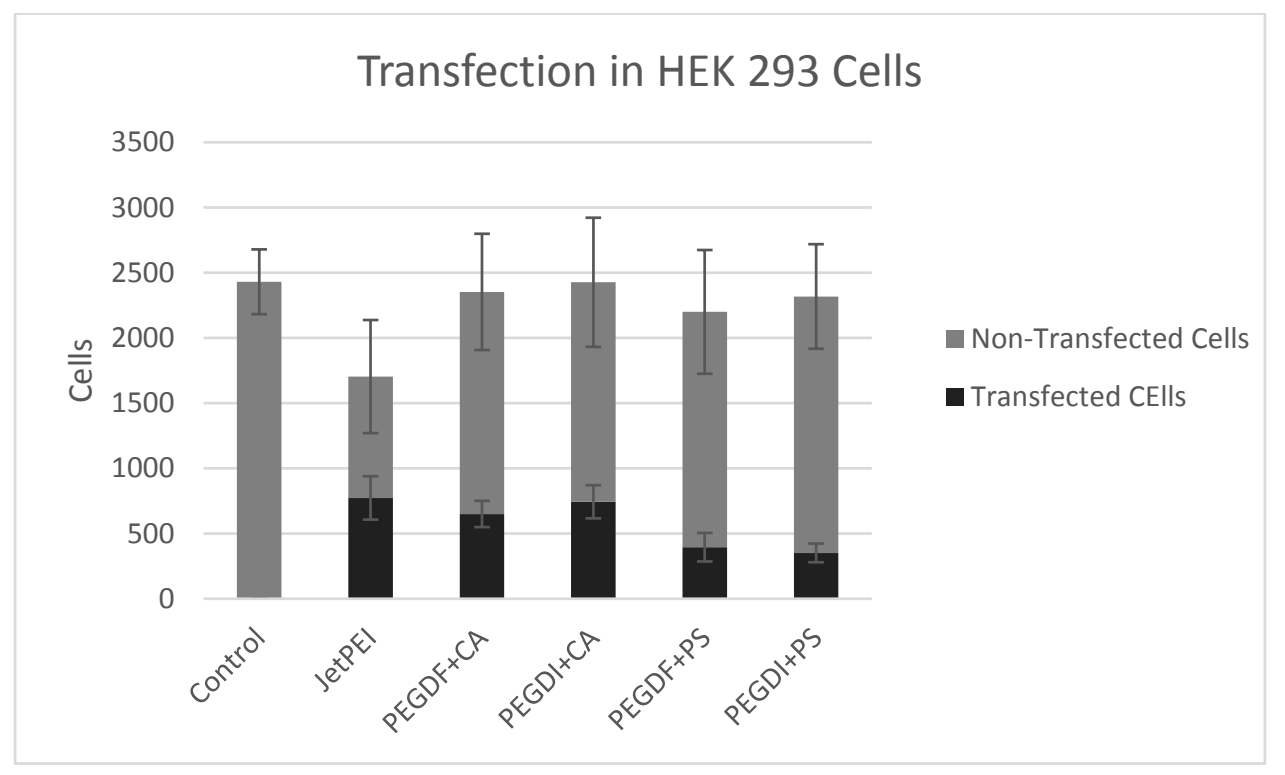

Figure 12. Transfection in HEK293 cells with PEGDFI+CA, PEGDI+CA, PEGDF+PS, PEGDI+PS, and JetPEI. These were tabulated cell count values from Cell Profiler image analysis. Values are given as mean \pm standard deviation $(n=3)$. 


\section{CHAPTER 5 DISCUSSION AND CONCLUSSIONS}

\subsection{Characterization of PEGDF and PEGDI polymers}

The molecular weight (MW) of day 2 PEGDF and PEGDI polymers were 2995

and 2550 Da, respectively. This is consistent with the literature that polycondensation of difunctional monomers yield low molecular weight polymers (29). A change in MW from day 1 to day 2 in GPC data showed polymer elongation by esterification of monomers. Day 2 samples were selected for further consideration in modification due to the absence of monomers in the GPC data.

Figure 2 shows the theoretical chemical structure of PEGDF and PEGDI. Key characteristics of the polymer includes ester bonds, double bonds, and a long hydrocarbon chain. The region of Raman spectra above $1000 \mathrm{~cm}^{-1}$ is known as the characterization region-where discernible functional groups can be identified. The Raman spectra of the PEGDF and PEGDI polymers shows characteristic peaks at 1735 $\mathrm{cm}^{-1}$ which signals the presence of ester bonds within the polymer backbone (31). This should be expected due polymer formation is by esterification or the formation of ester bonds. Raman spectra data also shows the presence of a peak at $1635 \mathrm{~cm}^{-1}$, signifying the presence of double bonds within the polymer backbone-necessary for further modification of the PEGDF and PEGDI polymers. The spectra data also shows peaks at $725 \mathrm{~cm}^{-1}$, which is seen only in long chain alkanes (31).

DLS results shows modified polymer and DNA polyplexes to be between the ranges of 130-170 $\mathrm{nm}$ which is an acceptable range for endosomal uptake for in vitro studies (18). There are varying reports of the perfect range of DNA polyplexes size for 
cellular uptake. Wagner et al observed that smaller polyplex size $(<100 \mathrm{~nm})$ leads to higher in vitro gene transfection of cell mediated uptake is by receptor mediated endocytosis but reports have also shown that polyplexes up to $500 \mathrm{~nm}$ are capable of cellular transfection (18). The zeta potential of a cationic polymer (CP) determines the surface charges of the polyplexes. CPs with surface potentials between the ranges of 20 $\mathrm{mV}$ to $40 \mathrm{mV}$ are sufficient in binding DNA and allowing for cellular transfection. Unfortunately, zeta potential was not measured for the modified PEDGF and PEDGI polymers but it is reasonable to assume that it is within that range since other studies have shown that the polymers are capable of binding DNA.

The PDI values were higher than 0.3 which can indicate a non-homogenous formulation of polyplexes (42). Some of the DLS results showed readings of two possible diameters, $>1500 \mathrm{~nm}$ and $<170 \mathrm{~nm}$. The larger diameter readings had a smaller intensity reading indicating a smaller concentration of particles. These large particles could be a result of sedimentation and or aggregation of free floating CPs.

\subsection{DNA binding by modified polymers}

Binding DNA is a basic requirement for cationic polymers to allow for transfection into cells. The gel binding assay was an important test that allowed for rapid identification of successful PEGDF and PEGDI nucleophilic addition by CA and PS, since successfully reacted polymers are capable of binding DNA and retarding its migration through the agarose gel. Looking at Figure 6a, we can see that all four modified polymers, PEGDF-PS, PEGDI-PS, PEGDI-CA, and PEGDF-CA were capable of retarding the migration of DNA through the agarose gel. Figure 6b shows that the 
PEGDF-PS and PEGDI-PS were also capable of preventing bromophenol blue (a negatively charged dye) from migrating through the agarose gel. This is probably due to the fact that protamine sulfate has a higher ratio of $\mathrm{N}$ to $\mathrm{P}$ then compared to the Cys-Arg8 peptide, so the PEGDF-PS and PEGDI-PS polymers carry a higher surface charge.

\subsection{In vitro cytotoxicity analysis of modified PEGDF/I polymers}

The alamar blue assay is a good indicator of cell viability by determining cells capabilities of reducing resazurin to resorufin—cells that are not healthy will be less capable of this reducing capability. JetPEI is a commercially available reagent that is known to exhibit high toxicity and decreased cell viability (40), was used as a negative control. Students t-test showed that the difference in mean fluorescence value on day 4 samples between PEGDF-PS, PEGDI-PS and JetPEI when compared to the control was statistically significant. The difference in mean fluorescence values of PEGDF-CA and PEGDI-CA when compared to the control group day 4 showed no statistically significance, thus PEGDF-CA and PEGDI-CA do not exhibit cytotoxic effects.

PEGDF and PEGDI polymers by themselves do not exhibit cytotoxicity since they can be readily broken down by hydrolysis of the ester bonds into their monomer components of PEG and DDA, both which can be metabolized by cells for energy. The toxic effects of polymers that have PS attachment can be attributed to its high surface charge. Increases in cationic surface charges for most NPs correlates to a greater cytotoxicity in non-phagocytic cells (41).

5.4 Cell Profiler image analysis 
Cell Profiler demonstrated that it is capable of doing a cell count both in brightfield and fluorescence images. Image analysis through Cell Profiler requires optimal threshold values to filter out noise and get a clear count of cells in bright field and fluorescence microscopy images. From the cell count, we were able to get a representation of the efficiency of transfection in HEK 293 cells. However, the imaging algorithms have a capacity to undercount or over-count based upon the threshold established (Figure 8). Nevertheless, this over-counting and under-counting error can be negated since the same thresholds will be applied to all the image sets.

\subsection{Transfection of HEK 293 cells}

Transfection in HEK 293 cells with modified PEGDF and PEGDI polymers were successful but showed varied efficiency. PEGDF-PS and PEGDI-PS had very low transfection efficiency of around 18\% and 15\%, respectively. PEGDF-CA and PEGDICA showed slightly better transfection efficiency of $27.8 \%$ and $30.7 \%$. JetPEI, a commercially available reagent was shown to have an efficiency of around $45 \%$, which is close to its expected efficiency. The varied efficiency between polymers modified by CA and PS ligands can possibly be explained by the characteristics of the cationic polymers. PEGDF and PEGDI polymers modified with PS exhibit a higher charge potential as can be deduce from its ability to bind bromophenol blue in the gel binding assay experiment. This higher charge density leads to a stronger affinity for negatively charged DNA. Also, it is possible that once inside the cytoplasm of cells the protamine sulfate ligands can prevent degradation of polymeric vesicles for release of pTurboGFP plasmids.

\subsection{Conclusion}


PEGDF and PEGDI polymers modified by the Michael addition of protamine sulfate (PS) and CysArg8 (CA) showed that they are capable of binding and condensing DNA into compact polyplexes. Polymers modified with PS are found to be cytotoxic, whereas polymers modified with CA are not. Transfection in HEK 293 with modified polymers were successful but showed varying efficiency. PEGDF+CA and PEGDI+CA showed transfection efficiency that ranges between $26-32 \%$. This is still lower in efficiency than commercially available JetPEI, but the tradeoff in non-cytotoxic nature of PEGDF+CA and PEGDI+CA showed that these polymers could be promising candidates for further consideration. 


\section{References}

1. Mulligan R. The Basic Science of Gene Therapy. Science. 14 May 1993; 260: 926931.

2. Kaufmann K, Buning H, Galy A, Schambach A, and Grez M. Gene Therapy on the move. EMBO Mol Med. 19 August 2013; 5:1-20.

3. Pfeifer A and Verma I. Gene Therapy: Promises and Problems. Annual Rev. Genomics Human Genetics. 2001. 2:177-211.

4. Mancheno-Corvo P and Martin-Duque P. Viral gene therapy. Clinical Transl Oncol. 2006. 12:858-67

5. Touchefeu Y, Harrington K J, Galmiche J P, and Vasssaux G. Review article: gene therapy, recent developments and future prospects in gastrointestinal oncology. Alimentary Pharmacology and Therapeutics. 2010. 32: 953-968.

6. Giacca M and Zacchigna S. Virus-mediated gene delivery for human gene therapy. Journal of controlled release. 2012. 161:377-388.

7. Li S-D Huang L. Gene therapy progress and prospects: non-viral gene therapy by systemic delivery. Gene Therapy. 2006. 13:1313-1319.

8. Al-Dosari M and Gao X. Nonviral Gene Delivery: Principle, Limitations, and Recent Progress

9. Thomas M and Klibanov A M. Non-viral gene therapy: polycation-mediated DNA delivery. Applied Microbiology Biotechnology. 2003. 62:27-34.

10. Panyam J and Labhastewar. Biodegradable nanoparticles for drug and gene delivery to cells and tissue. Advanced Drug Delivery Reviews. 2012. 64:61-71.

11. Morille M Passirani C Vonarbourg A Clavreul A and Benoit J P. Progress in developing cationic vectors for non-viral systemic gene therapy against cancer. Biomaterials. 2008; 29:3477-3496.

12. Rejman J, Bragonzi A, and Conese M. Role of clathrin- and caveolae-mediated endocytosis in gene transfer mediated by lipo- and polyplexes. Molecular Therapy. 2005; 12(3):468-74.

13. Sunshine et al. Uptake and transfection with polymeric nanoparticles are dependent on polymer end-group structure, but largely independent of nanoparticles physical and chemical properties. Molecular Pharmaceutics. 2012; 9: 3375-3383.

14. Patil S, Rhodes D and Burgess D. DNA-based therapeutics and DNA Delivery Systems: A comprehensive review. The AAPS Journal. 2005: 61-77. 
15. Liang W and Law J. Endosomal escape pathways for non-viral nucleic acid delivery systems. InTech. 2012: 429-456.

16. Huotari J and Helenius A. Endosome maturation. The Embo Journal. 2011; 30:34813500 .

17. Mady M M, Mohmammed W, El-Guendy N and Elsayed A.A. Effect of polymer molecular weight on the DNA/PEI polyplexes properties. Romanian J. Biophys. 2011: 21:151-165

18. Varkouhi A, Mountrichas G, Schiffelers R, Lammers T, Storm G, Pispas S and Hennink W. Polyplexes based on cationic polymers with strong nucleic acid binding properties. European Journal of Pharmaceutical Sciences. 2012; 45:459-466.

19. Zalipsky S. Chemistry of polyethylene glycol conjugates with biologically active molecules. Advance Drug Delivery Reviews. 1995; 16:157-182.

20. Miller A. Cationic Liposome for gene therapy. Angew. Chem. Int. Ed. 1998;

37:1768-1785.

21. Liu T, Yin J, Shang B, Min Z, He H, Jiang J, Chen F, Zhen Y, Shao R. Silencing of hdm2 oncogene by siRNA inhibits p53-dependent human breast cancer. Cancer Gene Therapy. 2004; 11:748-756.

22. Salinari S, Bertuzzi A, Gandolfi A, Greco A, Scarfone A, Manco M and Mingrone G. Dodecanedioic acid overcome metabolic inflexibility in type 2 diabetic subjects. Am J

Physiol Endocrinol Metab. 2006; 291:1051-1058.

23. Mather B, Viswanathan K, Miller K, Long T. Michael addition reactions in macromolecular design for emerging technologies. Progress in Polymer Science. 2006; 31:487-531.

24. Yasuda M, Chiba K, Ohigashi N, Katoh Y, and Baba A. Michael Addition of Stannyl Ketone Enolate to $\alpha, \beta$-Unsaturated Esters Catalyzed by Tetrabutylammonium Bromide and an ab Initio Theoretical Study of the Reaction Course. Journal of the American Chemical Society. 2003; 125: 7291-7300.

25. Thomas $P$ and Smart T. HEK293 cell line: a vehicle for the expression of recombinant proteins. Journal of pharmacological and toxicology methods. 2005; 51:187-200.

26. Malvern. Malvern Zetasizer Nano range for DLS, ELS, SLS, and microheology. $<$ http://www.malvern.com/labeng/products/zetasizer/zetasizer_nano.htm>

27. Efreniv E, Ariese F and GOoijer C. Achievements in resonance Raman spectroscopy Review of a technique with a distinct analytical chemistry potential. Analytica Chimica Act. 2008: 119-134. 
28. Sawant R, Sriraman S, Navarro G, Biswas S, Dalvi R and Torchilin V.

Polyethyleneimine-lipid conjugate-base $\mathrm{pH}$-sensitive micellar carrier for gene delivery.

Biomaterials. 2012: 33;3942-3951.

29. Guo J, Cheng W, Gu J, Ding C, Qu X, Yang Z, and O’Driscoll C. Systemic delivery of therapeutic small interfering RNA using a pH-triggered amphiphilic poly-L-lysine nanocarrier to suppress prostrate cancer growth. European Journal of Pharmaceutical Sciences. 2012; 45: 521-532

30. Mansouri S, Lavigne P, Corsi K, Benderdour M, Beaumont E and Fernandes J. Chitosan-DNA nanoparticles as non-viral vectors in gene therapy strategies to improve transfection efficacy. European Journal of Pharmaceutics and Biopharmaceutics. 2004; 57: 1-8.

31. Hu F-Q, Chen W, Zhao M, Yuan H, and Du Y. Effective antitumor gene therapy delivered by polyethylenimine-conjugated stearic acid-g-chitosan oligosaccharide micelles. Gene Therapy. 2013; 20: 597-606.

32. Goldburg W. Dynamic light scattering. American Journal of Physics. 1999; 67: 11521160

33. ThermoFisher Scientific. AlamarBlue Cell Viability Assay Protocol. 2015. <https://www.thermofisher.com/us/en/home/references/protocols/cell-and-tissueanalysis/cell-profilteration-assay-protocols/cell-viability-with-alamarblue.html>

34. Vroman I and Tighzer L. Biodegradable Polymers. Materials. 2009; 2:307-344

35. University of Colorado, Boulder. IR: Spectroscopy Tutorial: Alkanes. Chemistry and Biochemistry Department. 2011.

< http://orgchem.colorado.edu/Spectroscopy/irtutor/alkanesir.html>

36. Dennis A. Raman spectroscopy of edible oils and fats. Application Note: Raman Spectroscopy. Perkin Elmer.

<http://www.perkinelmer.com/PDFs/downloads/APP_RamanSpectroscopyOfEdible Oils AndFats.pdf $>$

37. Becattini G, Mattos LS, Caldwell DG. A novel framework for automated targeting of unstained living cells in bright field microscopy. 2011 IEEE International Symposium on Biomedical Imaging: From Nano to Macro. 195-198.

38. Selinummi J, Ruusuvuori P, Podolsky I, Ozinsky A, Gold E, Yli-Harja O, Aderem A, Shmulevich I. Bright field microscopy as an alternative to whole cell fluorescence in automated analysis of macrophage images. PLoS One. 2009 Oct 22;4(10):e7497

39. Drey LL, Graber MC, Bieschke J. Counting unstained, confluent cells by modified bright-field microscopy. Biotechniques. 2013 Jul;55(1):28-33. 
40. Chudy, A, Baczynska D, Skora J, Gebarowska E, Pupka A, and Dobosz T. Transfection efficiency and cytotoxicity of transfection reagents in human umbilical vein endothelial cells.

41. Frohlich E. The role of surface charge in cellular uptake and cytotoxicity of medical nanoparticles. Int J Nanomedicine. 2012; 7:5577-5591. 